\title{
Debt Overhang in a Business Cycle Model
}

\author{
Filippo Occhino ${ }^{\dagger} \quad$ Andrea Pescatori ${ }^{\ddagger}$
}

December 2011

\begin{abstract}
We study the macroeconomic implications of the debt overhang distortion. In our model, the distortion arises because investment is non-contractible - when a firm borrows funds, the debt contract cannot specify or depend on the firm's future level of investment. After the debt contract is signed, the probability that the firm will default on its debt obligation acts like a tax that discourages new investment by the firm, because the marginal benefit of that investment will be reaped by the creditors in the event of default. We show that the distortion moves counter-cyclically - it increases during recessions, when the risk of default is high. Its dynamics amplify and propagate the effects of shocks to productivity, government spending, volatility and funding costs. Both the size and the persistence of these effects are quantitatively important. The model replicates important features of the joint dynamics of macro variables and credit risk variables, like default rates, recovery rates and credit spreads.

Keywords: Debt Overhang, Financial Frictions, Financial Accelerator, Default, Credit Risk.

JEL Classification Number: E32, E44.
\end{abstract}

\section{Introduction}

We investigate the macroeconomic implications of a financial distortion that arises when the burden of some pre-existing debt - the debt overhang - weighs on a firm's investment decision. When the firm is so leveraged that it risks defaulting on its debt obligation, it anticipates that the marginal benefit of any new investment will be reaped by its creditors in the event of default. Hence, the higher the probability of default, the lower the marginal return that the firm expects to receive from its investment, the smaller its incentive to invest. The probability of default acts like a tax that discourages the firm's investment creating a wedge between the socially optimal level of investment and the firm's privately optimal one. The sub-optimality of the investment choice stems from the

\footnotetext{
${ }^{\dagger}$ Research Department, Federal Reserve Bank of Cleveland, 1455 East 6th Street, Cleveland, OH 44114. E-mail: filippo.occhino@clev.frb.org. The views expressed herein are those of the authors and do not necessarily reflect those of the Federal Reserve Bank of Cleveland or of the Board of Governors of the Federal Reserve System.

${ }^{\ddagger}$ Research Department, International Monetary Fund, 700 19th Street, N.W., Washington, D.C. 20431. E-mail: apescatori@imf.org. The views expressed herein are those of the authors and should not be attributed to the IMF, its Executive Board, or its management.
} 
fact that the firm does not internalize the positive effect of its investment choice on its creditors' payoff in the event of default. ${ }^{1}$

The impact of debt overhang is not limited to investment in physical capital. It also discourages other variable costs and discretionary decisions such as the exercise of real options, the effort exerted by managers and executives, labor utilization (hours per worker), hiring and training, and expenditures incurred in order to maintain and improve production and sales. $^{2}$ In particular, when a firm decides whether to hire, it weighs the current search, recruiting, and training costs against the future benefits offered by the additional productive worker. Just as debt overhang leads firms to under-invest in physical capital, it constrains its investment in labor.

We show that the debt overhang distortion arises naturally in environments where the investment in capital and labor of a limited liability firm is non-contractible, i.e., the debt contract cannot specify or depend on the firm's future investment and hiring decisions. This friction creates a moral hazard setting: The non-contractible investment choice of the firm (the agent's hidden action) affects the payoff of the lender (the principal). Following Innes (1990), we show that the constrained-optimal contract is risky debt, and that the debt overhang leads to under-investment.

We incorporate the debt overhang distortion in a business cycle model and we find that it can dramatically amplify and propagate the effects of productivity, government spending, volatility and funding cost shocks. There are two positive feedback loop mechanisms at work, both acting through the probability of default. First, shocks that increase the probability of default, exacerbate the debt overhang distortion, and decrease investment; in turn, a lower level of investment further increases the probability of default, in a static feedback amplification mechanism. Also, shocks that increase the probability of default and decrease investment, have a persistent negative effect on the firm's capital, thereby increasing the probability of default persistently over time, in a dynamic feedback propagation mechanism.

Through these mechanisms, productivity and government spending shocks have ampler and more persistent effects than in a standard model without debt overhang. In addition, shocks that increase the volatility of productivity and funding cost shocks, which do not have any effect in the standard model, increase the probability of default, exacerbate the debt overhang distortion, and have ample and persistent negative effects on investment.

Recent empirical work in corporate finance has stressed the quantitative importance of the overhang effect of corporate debt. Hennessy (2004) shows that debt overhang distorts both the level and composition of investment, with under-investment being more severe for long-lived assets. He finds a statistically significant debt overhang effect regardless of firms' ability to issue additional secured debt. Using firm level data and studying a large variety of credit frictions, Hennessy, Levy and Whited (2007) document that the

\footnotetext{
${ }^{1}$ Myers (1977) is the seminal article describing how existing corporate debt leads to sub-optimal investment decisions.

${ }^{2}$ Myers (1977) emphasizes the wide range of discretionary decisions distorted by debt overhang: "The discretionary investment may be maintenance of plant and equipment. It may be advertising or other marketing expenses, or expenditures on raw materials, labor, research and development, etc. All variable costs are discretionary investments ... This is not simply a matter of maintaining plant and equipment. There is continual effort devoted to advertising, sales, improving efficiency, incorporating new technology, and recruiting and training employees. All of these activities require discretionary outlays. They are options the firm may or may not exercise; and the decision to exercise or not depends on the size of payments that have been promised to the firms creditors."
} 
magnitude of the debt overhang drag on investment is substantial, especially for distressed (high probability of default) firms. They find that debt overhang decreases the level of investment by approximately 1 to 2 percent for each percent increase in the leverage ratio of long-term debt to assets. Moyen (2007) measures a large overhang cost, a loss of approximately 5 percent of firm value, both with long-term debt and with short-term debt. Chen and Manso (2011) show that the debt overhang cost increases substantially in the presence of macroeconomic risk, peaking during recessions at 3.5 percent and 8.6 percent of firm value for low and high leverage firms, respectively.

While the corporate finance and international finance literature have long acknowledged the debt overhang effect, ${ }^{3}$ our article is the first to introduce debt overhang in an otherwise standard business cycle framework, and to evaluate quantitatively the resulting amplification and propagation mechanisms of shocks. ${ }^{4}$ Whereas we study how debt overhang reduces the firms' benefit of investing, the recent literature has focused on financial frictions that raise the firms' cost of investing, or directly constrain the level of investment. On one hand, a strand of the financial frictions literature, following the contribution of Kiyotaky and Moore (1997), assumes that there is no enforceability for unsecured lending, and studies equilibria where loans are fully collateralized and no default occurs. Since collateral values are pro-cyclical, the credit constraint binds less during expansions, which induces credit cycles. However, a common criticism of credit constraint models is that they cannot generate large amplification for plausible parameter values. ${ }^{5}$ On the other hand, most of the financial frictions literature has focused on how agency costs associated with the asymmetric information between the lender and the firm affect the cost of credit and thus the level of investment. In the works of Bernanke and Gertler (1989), Carlstrom and Fuerst (1997), and Bernanke, Gertler and Gilchrist (1999), monitoring resources are used whenever defaults occur. Ex-ante, this generates an external finance premium that contributes to amplify business cycle fluctuations. Section 3.4 compares this framework with our debt overhang model. We find that, although the qualitative predictions of the two frameworks are close, the amplification mechanism generated by the debt overhang distortion is quantitatively more important. ${ }^{6}$

The paper is organized as follows: Section 2 describes the economy, with a focus on the financial friction, the constrained-optimal contract, and the debt overhang distortion; Section 3 studies the amplification and propagation mechanisms, documents the model's quantitative predictions, and evaluates the model empirically; and Section 4 concludes.

\footnotetext{
${ }^{3}$ Because foreign debt effectively generates a tax on domestic investment, debt overhang effects have also been studied in the international finance literature. Examples are Krugman (1988) and Bulow and Rogoff (1991). See Obstfeld and Rogoff (1996, Sections 6.2.3 and 6.2.4) for a review.

${ }^{4}$ Lamont (1995) studies how debt overhang can create multiple equilibria in which expectations determine economic activity. Philippon (2009) studies how the interaction of debt overhang in multiple markets can amplify shocks and even lead to multiple equilibria, and how governments can improve efficiency through bailouts and other policies during the renegotiation of the debt contract. Although these two papers substantially differ from ours as to motivation, focus, approach, model, and results, their conclusions complement and reinforce our findings.

${ }^{5}$ See Kocherlakota (2000) and Córdoba and Ripoll (2004). For an alternative result, see Cooley, Marimon and Quadrini (2004) who show that limited contract enforceability amplifies the impact of technology shocks.

${ }^{6}$ Some recent studies have documented the importance of financial shocks in accounting for business cycle fluctuations. Notable examples are Christiano, Motto and Rostagno (2007), Gilchrist, Ortiz and Zakrajsek (2009), and Jermann and Quadrini (2009). While we also study the impact of credit risk shocks on macroeconomic variables, the focus of our paper is on the propagation mechanism of standard macroeconomic shocks.
} 


\section{The model}

There are three sectors: an infinitely living representative household, a financial sector made of overlapping banks that live for two periods, and a production sector made of overlapping firms that live for two periods. Banks and firms are owned by the representative household.

Households are modeled in a standard way. They work, save and consume; they also make deposits to banks, provide equity funds to banks and firms, and receive equity payoffs, dividends, from them.

Firms make the hiring and investment decisions, and produce using labor and physical capital. Both factors of production are homogenous and can be freely reallocated across firms, and the relative price of investment to output is constant and normalized to 1. Labor contracts are signed and wages are paid one period in advance. As will be clear, this timing allows to capture the debt overhang distortion on labor demand described by Myers (1977) with a minimal departure from the standard business cycle model. It is consistent with articles in the macro literature with labor search, e.g. the seminal contribution of Merz (1995), where labor matches in the current period add to the stock of employment in the next period.

The debt overhang distortion arises from the interaction between banks and firms. At the beginning of each period, a continuum of mass 1 of banks and firms are born. Banks immediately receive deposits and equity funds from households. Firms, however, before being able to operate, need to receive an exogenously given amount of starting funds, $m$, from banks. Each firm, then, meets a bank, and the two sign a financial contract: In exchange for starting funds, $m$, the firm promises to repay the bank a payoff, $P$.

The financial contract is constrained optimal, subject to a financial friction: Both banks and firms have limited liability, and the firm's investment in capital and labor is non-contractible. We show that the constrained-optimal financial contract is of the risky-debt type: The firm will fully repay a face value $b$ only if the value of its output $y$ will turn out to be higher than the debt face value itself, otherwise, the firm will default and the bank will only be able to recover $y$.

After the debt contract is signed, the firm receives equity funds from households, and makes its hiring and investment decisions. Since the debt face value $b$ is given at the time of these decisions, and debt is risky, a debt overhang distortion arises: the firm does not internalize the full benefit of its hiring and investment choices and under-invests both in capital and labor.

The next period, the firm produces, and repays $P$ to the bank. After that, both the bank and the firm distribute everything that they have as dividends to the households and disappear.

\subsection{Households}

The utility function is $[u(c)-v(l)]$, with $u^{\prime}(c) \equiv c^{-\gamma}, \gamma>0$, and $v^{\prime}(l)=\phi l^{\varphi}, \phi>0, \varphi>0$. Households choose consumption demand $c_{t}$, labor supply $l_{t+1}$, and risk-free deposits $d_{t+1}$ to solve the following problem:

$$
\begin{aligned}
& \max _{\left\{c_{t}, l_{t+1}, d_{t+1}\right\}_{t=0}^{\infty}} E_{0}\left\{\sum_{t=0}^{\infty} \beta^{t}\left[u\left(c_{t}\right)-v\left(l_{t}\right)\right]\right\} \\
& \text { subject to: } c_{t}+d_{t+1} /\left(1+r_{t}\right)+z_{t}^{b}+z_{t}^{f}+T_{t}=w_{t+1} l_{t+1}+d_{t}+\pi_{t}^{b}+\pi_{t}^{f}
\end{aligned}
$$


and subject to a no-Ponzi-game constraint; given the initial values of the state, the contingent sequences of wage rates $\left\{w_{t+1}\right\}_{t=0}^{\infty}$, risk-free rates $\left\{r_{t}\right\}_{t=0}^{\infty}$, lump-sum taxes $\left\{T_{t}\right\}_{t=0}^{\infty}$, equity injections $\left\{z_{t}^{b}, z_{t}^{f}\right\}_{t=0}^{\infty}$ to newly formed banks and firms, and dividends $\left\{\pi_{t}^{b}, \pi_{t}^{f}\right\}_{t=0}^{\infty}$ from exiting banks and firms. Notice that both labor is determined and wages are paid one period in advance.

Households' necessary conditions are

$$
\begin{aligned}
u^{\prime}\left(c_{t}\right) /\left(1+r_{t}\right) & =E_{t}\left\{\beta u^{\prime}\left(c_{t+1}\right)\right\} \\
u^{\prime}\left(c_{t}\right) w_{t+1} & =\beta v^{\prime}\left(l_{t+1}\right)
\end{aligned}
$$

The first equation governs the optimal consumption path depending on the risk-free rate $r$, while the second equation determines the consumption-labor choice depending on the wage rate $w$.

\section{$2.2 \quad$ Banks}

The banking sector is made of overlapping banks that live for two periods. At any time $t$, a new bank collects deposits $d_{t+1} /\left(1+r_{t}\right)$ and equity funds $z_{t}^{b}$ from households, meets a firm and signs a financial contract exchanging current starting funds, $m$, for a future payoff, $P_{t+1}$. The time $t$ budget constraint is $m \leq d_{t+1} /\left(1+r_{t}\right)+z_{t}^{b}$.

The next period, the bank receives $P_{t+1}$ from the firm, repays deposits $d_{t+1}$, distributes dividends $\pi_{t+1}^{b}$, and exits the scene. The time $t+1$ budget constraint is $\pi_{t+1}^{b}+d_{t+1} \leq P_{t+1}$.

Since banks are owned by households, they discount future dividends using the households' stochastic discount factor

$$
\Lambda_{t, t+1} \equiv \beta u^{\prime}\left(c_{t+1}\right) / u^{\prime}\left(c_{t}\right)
$$

Banks, then, maximize the objective function $E_{t}\left\{\Lambda_{t, t+1} \pi_{t+1}^{b}\right\}-z_{t}^{b}$ subject to the two period budget constraints:

$$
\begin{gathered}
E_{t}\left\{\Lambda_{t, t+1} \pi_{t+1}^{b}\right\}-z_{t}^{b} \\
\text { subject to } z_{t}^{b}=m-d_{t+1} /\left(1+r_{t}\right) \\
\pi_{t+1}^{b}=P_{t+1}-d_{t+1}
\end{gathered}
$$

The necessary condition for $d_{t+1}$ is:

$$
1 /\left(1+r_{t}\right)=E_{t}\left\{\Lambda_{t, t+1}\right\}
$$

After substituting the two budget constraints with equality and using the necessary condition, the bank's objective function becomes:

$$
\begin{aligned}
V^{b}\left(P_{t+1}\right) & \equiv E_{t}\left\{\Lambda_{t, t+1}\left[P_{t+1}-d_{t+1}\right]\right\}-\left[m-d_{t+1} /\left(1+r_{t}\right)\right] \\
& =E_{t}\left\{\Lambda_{t, t+1} P_{t+1}\right\}-m
\end{aligned}
$$

The condition that banks' expected discounted profits from lending activities are nonnegative is $E_{t}\left\{\Lambda_{t, t+1} P_{t+1}\right\}-m \geq 0$. 


\section{$2.3 \quad$ Firms}

The production sector is made of overlapping firms that live for two periods. Firms use capital $k_{t+1}$ and labor $l_{t+1}$ to produce a homogenous output $y_{t+1}$,

$$
y_{t+1} \equiv \omega_{t+1} \theta_{t+1} A_{t+1} f\left(k_{t+1}, l_{t+1}\right)
$$

where $f(k, l) \equiv\left(k^{\alpha} l^{1-\alpha}\right)^{\tau}$ is a decreasing returns to scale production function, $\alpha \in(0,1)$, $\tau \in(0,1) ; \theta_{t+1}$ is an aggregate technology shock; $\omega_{t+1}$ is an idiosyncratic productivity shock, i.i.d. across all firms. The aggregate term $A_{t+1} \equiv A\left(K_{t+1}^{\alpha} L_{t+1}^{1-\alpha}\right)^{1-\tau}, A>0$, is an externality that depends on aggregate capital $K$ and aggregate labor $L$ (where $k=K$ and $l=L$ in equilibrium). Adding this term guarantees that the production function is constant returns to scale at the aggregate level.

The idiosyncratic productivity shock $\omega$ follows the law of motion:

$$
\begin{aligned}
\ln \left(\omega_{t+1}\right) & =\sigma_{\omega, t} \varepsilon_{\omega, t+1} \\
\ln \left(\sigma_{\omega, t+1} / \sigma_{\omega}\right) & =\rho_{\omega, \sigma} \ln \left(\sigma_{\omega, t} / \sigma_{\omega}\right)+\sigma_{\omega, \sigma} \eta_{\omega, t+1}
\end{aligned}
$$

where $\varepsilon_{\omega, t+1}$, all $i$, and $\eta_{\omega, t+1}$ are i.i.d. standard normal shocks. Aggregate productivity $\theta$ follows the law of motion:

$$
\begin{aligned}
\ln \left(\theta_{t+1}\right) & =\rho_{\theta} \ln \left(\theta_{t}\right)+\sigma_{\theta, t} \varepsilon_{\theta, t+1} \\
\ln \left(\sigma_{\theta, t+1} / \sigma_{\theta}\right) & =\rho_{\theta, \sigma} \ln \left(\sigma_{\theta, t} / \sigma_{\theta}\right)+\sigma_{\theta, \sigma} \eta_{\theta, t+1}
\end{aligned}
$$

where $\varepsilon_{\theta, t+1}$ and $\eta_{\theta, t+1}$ are two i.i.d. standard normal shocks. A firm's total productivity is the product of its idiosyncratic productivity $\omega$ and the aggregate productivity $\theta$. Notice that both the volatility of aggregate productivity and the volatility of idiosyncratic productivity are stochastic processes. The volatility $\sigma$ of a firm's log-total productivity $\ln (\omega \theta)$ is determined by

$$
\sigma_{t}^{2} \equiv \sigma_{\omega, t}^{2}+\sigma_{\theta, t}^{2}
$$

At any time $t$, a new firm needs a given amount of starting funds, $m$, to begin operations. The firm meets a bank and signs a financial contract exchanging current starting funds $m$ for a future payoff $P_{t+1}$. Once the contract is signed, the firm receives equity funds $z_{t}^{f}$ from households, buys capital goods $k_{t+1}$, hires labor $l_{t+1}$, and pays wages $w_{t+1} l_{t+1}$. The time $t$ budget constraint is $k_{t+1}+w_{t+1} l_{t+1} \leq m+z_{t}^{f}$. Again, notice that labor is determined and wages are paid one-period in advance.

The next period, the firm produces $y_{t+1}$, repays $P_{t+1}$ to the bank, sells the undepreciated capital $(1-\delta) k_{t+1}$ distributes dividends $\pi_{t+1}^{f}$, and exits the scene. The time $t+1$ budget constraint is $\pi_{t+1}^{f}+P_{t+1} \leq y_{t+1}+(1-\delta) k_{t+1}$, where $\delta \in(0,1)$ is the depreciation rate.

Since firms are owned by households, they discount future dividends using the households' stochastic discount factor $\Lambda_{t, t+1}$, the same discout factor that banks use. The firm's objective function is $E_{t}\left\{\Lambda_{t, t+1} \pi_{t+1}^{f}\right\}-z_{t}^{f}$, subject to the two period budget constraints:

$$
\begin{gathered}
E_{t}\left\{\Lambda_{t, t+1} \pi_{t+1}^{f}\right\}-z_{t}^{f} \\
\text { subject to } z_{t}^{f}=w_{t+1} l_{t+1}+k_{t+1}-m \\
\pi_{t+1}^{f}=y_{t+1}+(1-\delta) k_{t+1}-P_{t+1}
\end{gathered}
$$


After substituting the two budget constraints with equality, the firm's objective function becomes

$$
V^{f}\left(P_{t+1}, k_{t+1}, l_{t+1}\right) \equiv E_{t}\left\{\Lambda_{t, t+1}\left[y_{t+1}+(1-\delta) k_{t+1}-P_{t+1}\right]\right\}-\left[w_{t+1} l_{t+1}+k_{t+1}-m\right]
$$

where $y_{t+1} \equiv \omega_{t+1} \theta_{t+1} A_{t+1} f\left(k_{t+1}, l_{t+1}\right)$.

\subsection{The Optimal Contract}

The contract signed by the bank and the firm is constrained optimal subject to a financial friction: Both banks and firms have limited liability, and the firm's investment in capital and labor is non-contractible.

\section{Non-contractibility of investment.}

We assume that the contract cannot specify or depend on the firm's future investment in either capital or labor. Although a minimum investment level is required, the firm cannot commit to an exact investment level when signing the contract, and, afterwards, it is free to choose investment to maximize its own objective function The payoff of the contract, $P$, can depend on the firm's output $y$, i.e. $P=P(y)$, but cannot depend directly on capital $k$ or labor $l$.

This part of the friction is crucial for generating the debt overhang distortion. Since the non-contractible investment choice of the firm (the agent's hidden action) affects output $y$, the payoff $P(y)$ and the objective function of the bank (the principal), a moral hazard problem arises and under-investment follows. If the contract could directly set the investment level, the contract would prescribe the socially optimal one, and there would be no moral hazard problem or debt overhang distortion.

This highlights how the debt overhang distortion derives from an agency problem that is different in nature from the one considered in the financial accelerator literature. There, the agency costs are generated by asymmetric information on output - while investment is contractible. In our setup, instead, the output level is perfectly observable, but is only an imperfect signal of the hidden action, i.e. the level of investment in capital and labor. This generates a moral hazard problem, agency costs and a debt overhang distortion.

Assuming that investment and hiring decisions are not part of the contract is certainly realistic. Although covenants sometimes require a mininum investment level, banks generally leave the most important hiring and investment decisions to firms. As Freixas and Rochet (2008, page 143) point out:

It is characteristic of the banking industry for banks to behave as a sleeping partner in their usual relationship with borrowers. ${ }^{7}$ For this reason, it seems natural to assume that banks ignore the actions borrowers are taking in their investment decisions.. This is typically a moral hazard setup. The borrower has to take an action that will affect the return to the lender, yet the lender has no control over this action.

There may be several reasons why banks generally leave the most important investment and hiring decisions to firms. Firms have an obvious informational advantage on

\footnotetext{
${ }^{7}$ Regulation may even give incentives so that banks do not interfere with the choice of investment projects by the firms.
} 
the optimal level of hiring and investment. That optimal level is in general contingent on events occurring and information accumulating only after the debt contract is signed. The true investment level may be substantially different from the reported one: part of true investment, like effort and capacity utilization, is simply hard to report; and part of reported investment is not true investment but rather perquisite consumption by equity holders.

\section{Limited liability.}

Also, we assume that both banks and firms have limited liability, i.e. $0 \leq P(y) \leq y$ all $y$. The payoff cannot be negative and the firm's obligation is limited to the value of its output $y$.

This part of the friction also plays a role in generating the debt overhang distortion, because it rules out risk-free debt, i.e. $P=b$ with $b$ constant, from the menu of possible contracts. Without limited liability, the optimal contract would be risk-free debt, which would make the firm the residual claimant and give it full incentive to invest optimally.

\section{Monotonicity of the payoff function.}

In addition, we restrict the payoff function to be nondecreasing in output, i.e. $P\left(y_{1}\right) \leq$ $P\left(y_{2}\right)$ all $y_{1} \leq y_{2}$.

This reasonable restriction can be justified, along lines suggested by Innes (1990), assuming that the firm can costlessly revise its report on output upward. For instance, one easy way the firm can raise its report on output in the second period is by purchasing some goods, immediately re-selling them in the market, and reporting only the sale transaction. In this case, the above restriction is without loss of generality: If the payoff function were decreasing in output, the firm could diminish its liability by simply reporting a higher level of output; it would then be easy to construct an equivalent equilibrium with a non-decreasing payoff function and a truth-telling report on output.

\section{The contracting problem}

All constrained-optimal contracts maximize the firm's objective function subject to the limited liability and monotonicity assumptions, the firm's incentive-compatibility constraint, and the bank's participation constraint.

Let's momentarily drop the $t$ and $t+1$ subscripts. Let

$$
V^{f}(P(y), k, l) \equiv E\{\Lambda[y+(1-\delta) k-P(y)]\}-[w l+k-m]
$$

be the objective function of the firm, where $y \equiv \omega \theta A f(k, l)$, and let

$$
V^{b}(P(y)) \equiv E\{\Lambda P(y)\}-m
$$

be the objective function of the bank.

Let $\bar{V}^{b} \geq 0$ denote the minimum level of expected profits granted to the bank. The 
payoff, $P(y)$, of the constrained-optimal contract solves the following problem:

$$
\begin{aligned}
\underset{P(y), k^{*}, l^{*}}{\max } & V^{f}\left(P(y), k^{*}, l^{*}\right) \\
\text { subject to } & 0 \leq P(y) \leq y, \quad \text { all } y \\
& P\left(y_{1}\right) \leq P\left(y_{2}\right), \quad \text { all } y_{1} \leq y_{2} \\
& V^{f}(P(y), k, l) \leq V^{f}\left(P\left(y^{*}\right), k^{*}, l^{*}\right), \quad \text { all }(k, l) \in \Omega \\
& V^{b}\left(P\left(y^{*}\right)\right) \geq \bar{V}^{b}
\end{aligned}
$$

for given $\bar{V}^{b}$, where $\left(k^{*}, l^{*}\right)$ is the equilibrium investment and hiring choice made by the firm, and $y^{*} \equiv \omega \theta A f\left(k^{*}, l^{*}\right)$ is the corresponding output level. We assume that the contract requires a minimum investment level: The firm can freely choose investment in capital and labor in the set $\Omega \equiv\{(k, l): f(k, l) \geq \underline{e}\}$, where $\underline{e}>0$ is a strictly positive constant. The third constraint simply states that $\left(k^{*}, l^{*}\right)$ is the level of investment and hiring that maximizes the firm's objective function, while the fourth constraint is the bank's participation constraint. As $\bar{V}^{b}$ varies, the set of all constrained-optimal contracts, parameterized by $\bar{V}^{b}$, can be traced and characterized.

\section{The optimal contract is risky debt}

Appendix A shows that this problem is the same as the one studied by Innes (1990). Intuitively, the firm is choosing an effort level $e \equiv f(k, l)$, sustaining the cost

$$
\psi(e) \equiv \min _{k, l}\{w l+[1-E\{\Lambda\}(1-\delta)] k\} \text { subject to } f(k, l) \geq e
$$

where $\psi(e)$ is increasing and convex. Since $y=\omega \theta A e$, output given effort is distributed as a log-normal and its density function satisfies the monotone likelihood ratio property, i.e., a higher realization of output indicates a greater likelihood of higher effort.

Innes (1990) shows that the constrained-optimal contract is risky debt, ${ }^{8}$ i.e.,

$$
P(y) \equiv \min \{y, b\}
$$

for some face value of debt, $b$, that we will specify below at the end of this section.

Innes' result is intuitive. The constrained-optimal contract aims at encouraging the firm's investment. Since high output is more likely when investment is high, the contract assigns all the output to the bank whenever it is below a threshold $b$, whereas it assigns as much as possible to the firm (subject to the constraint that the payoff must be nondecreasing in output) whenever it is above the threshold $b .^{9}$

The face value, $b$, is determined by the bank's participation constraint

$$
E\left\{\Lambda \min \left\{y^{*}, b\right\}\right\}-m=\bar{V}^{b}
$$

The face value $b$ increases with both the starting funds $m$ and the bank's minimum expected discounted profits $\bar{V}^{b}$.

\footnotetext{
${ }^{8}$ See Bolton and Dewatripont (2005, Section 4.6.2) and Freixas and Rochet (2008, Section 4.4) for two nice expositions of Innes' result.

${ }^{9}$ As Bolton and Dewatripont (2005, page 163) put it, "when the downside of an investment is limited both for the entrepreneur and the investor, the closest one can get to a situation where the entrepreneur is a "residual claimant" is a (risky) debt contract."
} 
To select one specific contract among all possible constrained-optimal contracts, we need to select a value for $\bar{V}^{b}$, i.e. the minimum value for the bank's expected discounted profits. We focus on $\bar{V}^{b}=0$, which corresponds to assuming that there is free-entry in the banking sector, so the bank's outside option is zero, and the firm makes a take-it-orleave-it offer to the bank. In this case, the expected discounted value of the risky-debt payoff is equal to the loan amount $m$.

In a later section, however, we will show the impulse response functions to a shock to $\bar{V}^{b}$. This can be interpreted as an exogenous increase in the premium that banks charge for their loans and can proxy for shocks to several factors affecting firms' funding costs such as rents due to banking market structure and power, or shocks to risk and liquidity premiums.

\subsection{The debt overhang distortion}

We are now in a position to study how debt overhang distorts the firm's investment choices. Using the result that risky debt is the constrained-optimal contract, $P(y) \equiv$ $\min \{y, b\}$, the firm's optimization problem becomes

$$
\begin{aligned}
& \max _{\left\{\left(l_{t+1}, k_{t+1}\right) \in \Omega\right\}} E_{t}\left\{\Lambda_{t, t+1}\left[y_{t+1}+(1-\delta) k_{t+1}-\min \left\{y_{t+1}, b_{t+1}\right\}\right]\right\}-\left[w_{t+1} l_{t+1}+k_{t+1}-m\right] \\
& \text { where } y_{t+1} \equiv \omega_{t+1} \theta_{t+1} A_{t+1} f\left(k_{t+1}, l_{t+1}\right)
\end{aligned}
$$

given the stochastic discount factor $\Lambda$, the wage rate $w$, the starting funds $m$ and the debt face value $b$. Notice that, at the time when the firm chooses capital and labor, the debt face value, $b$, is given, which is what will generate the debt overhang distortion.

The firms' necessary conditions are ${ }^{10}$

$$
\begin{aligned}
1 & =E_{t}\left\{\Lambda_{t, t+1}\left[(1-\delta)+\partial y_{t+1} / \partial k_{t+1}\right]\right\}-\frac{\partial E_{t}\left\{\Lambda_{t, t+1} \min \left\{y_{t+1}, b_{t+1}\right\}\right\}}{\partial k_{t+1}} \\
w_{t+1} & =E_{t}\left\{\Lambda_{t, t+1}\left(\partial y_{t+1} / \partial l_{t+1}\right)\right\}-\frac{\partial E_{t}\left\{\Lambda_{t, t+1} \min \left\{y_{t+1}, b_{t+1}\right\}\right\}}{\partial l_{t+1}}
\end{aligned}
$$

For both equations, the last term on the right hand side is the debt overhang correction term. Without that term, the equations would determine the socially optimal level of investment (both in capital and labor). The presence of this term implies that the level of investment is less than the socially optimal one. The debt overhang correction is present because part of the benefits of the firm's investment choice accrues to the bank, and the firm does not internalize this positive externality on the bank's profits.

Although risky debt is the constrained-optimal contract, it still cannot encourage the socially optimal level of investment. Innes shows that "a "first best" effort choice is not achieved ... With a debt contract, the entrepreneur still works "too little" (relative to a first best)." In fact, Bolton and Dewatripont (2005, pages 167-168) point out that

"[...] when external financing is constrained by limited liability, it will generally not be possible to mitigate the debt overhang problem [...] by

\footnotetext{
${ }^{10}$ The parameter $\tau$ controlling the returns-to-scale at the firm level is set low enough so that $f(k, l)$ is sufficiently concave and the second-order condition for optimality is satisfied in steady state: $\left(1+\frac{\Phi^{\prime}\left(d_{1}\right)}{\Phi\left(d_{1}\right) \sigma}\right) \tau<1$.
} 
looking for other forms of financing besides debt. Indeed, Innes's result indicates that under quite general conditions it is not possible to get around this problem by structuring financing differently. Debt is already the financial instrument that minimized this problem when there is limited liability."

To gain intuition on these crucial necessary conditions, notice that $A_{t+1}, k_{t+1}, l_{t+1}$ and $b_{t+1}$ are all known in period $\mathrm{t}+1$, and that $y_{t+1}=\omega_{t+1} \theta_{t+1} A_{t+1} f\left(k_{t+1}, l_{t+1}\right)$ is $\log$ normally distributed with standard deviation equal to $\sigma_{t}$. Then, well-known analytical results holding for log-normally distributed random variables yield: ${ }^{11}$

$$
\begin{aligned}
\frac{\partial E_{t}\left\{\min \left\{y_{t+1}, b_{t+1}\right\}\right\}}{\partial k_{t+1}} & =E_{t}\left\{\partial y_{t+1} / \partial k_{t+1}\right\}\left[1-\Phi\left(d_{1, t}\right)\right] \\
\frac{\partial E_{t}\left\{\min \left\{y_{t+1}, b_{t+1}\right\}\right\}}{\partial l_{t+1}} & =E_{t}\left\{\partial y_{t+1} / \partial l_{t+1}\right\}\left[1-\Phi\left(d_{1, t}\right)\right] \\
\text { where } d_{2, t} & \equiv \frac{E_{t}\left\{\ln \left(y_{t+1}\right)\right\}-\ln \left(b_{t+1}\right)}{\sigma_{t}} \text { and } d_{1, t} \equiv d_{2, t}+\sigma_{t}
\end{aligned}
$$

where $\Phi(\cdot)$ is the cumulative distribution function of the standard normal random variable.

Using these results and the fact that the expectation of a product is equal to the product of the expectations plus a covariance term, $E(x z)=E(x) E(z)+\operatorname{Cov}(x, z)$, we can express the firm's necessary conditions as follows:

$$
\begin{aligned}
1 & =E_{t}\left\{\Lambda_{t, t+1}\right\}\left[(1-\delta)+E_{t}\left\{\partial y_{t+1} / \partial k_{t+1}\right\} \Phi\left(d_{1, t}\right)\right]+\chi_{k, t} \\
w_{t+1} & =E_{t}\left\{\Lambda_{t, t+1}\right\} E_{t}\left\{\partial y_{t+1} / \partial l_{t+1}\right\} \Phi\left(d_{1, t}\right)+\chi_{l, t}
\end{aligned}
$$

where $\chi_{k, t} \equiv \partial \operatorname{Cov}_{t} / \partial k_{t+1}, \chi_{l, t} \equiv \partial \operatorname{Cov}_{t} / \partial l_{t+1}$, and $\operatorname{Cov}_{t} \equiv \operatorname{Cov}_{t}\left(\Lambda_{t, t+1}, \min \left\{y_{t+1}, b_{t+1}\right\}\right){ }^{12}$

To interpret these conditions notice that $\Phi\left(d_{2, t}\right)$ is the probability that the debt will be fully repaid, so $1-\Phi\left(d_{2, t}\right)$ is the default probability. $\Phi\left(d_{1, t}\right)$ can be similarly interpreted as an (adjusted) repayment probability. The difference between $\Phi\left(d_{1, t}\right)$ and $\Phi\left(d_{2, t}\right)$ is quantitatively negligible and does not play any role in our model. With regard to $d_{1, t}$ and $d_{2, t}$, they both can be interpreted as distances to default.

These two equations are similar to the corresponding ones of a standard real business cycle model with labor-in-advance, except for the presence of the (adjusted) probability of repayment $\Phi\left(d_{1, t}\right)$. When output, $y$, exceeds the face value of the debt, $b$, an event that occurs with probability $\Phi\left(d_{1}\right)$, the firm repays its liabilities and receives the full marginal return from its investment, as in the standard case. However, when output falls short of debt, the firm defaults, the bank seizes its output, and the firm does not receive the marginal return from its investment. Hence, the lower the repayment probability $\Phi\left(d_{1}\right)$, the lower the firm's expected marginal return on investment, the lower its incentive to invest. The default probability $1-\Phi\left(d_{1}\right)$ appears as a wedge in both the investment and

\footnotetext{
${ }^{11}$ These results are routinely used in option pricing to compute the price of options and its derivatives (the greeks). Appendix B details the computation of the derivatives, which involves two terms canceling each other out.

${ }^{12}$ The $\chi$ terms on the right hand sides of the two equations (the two derivatives of the covariance) can be loosely interpreted as risk premia associated with the co-movement between the risky debt payoff and the stochastic discount factor. In fact, the terms are identically zero both in the absence of aggregate uncertainty and when the default probability is zero. Their contribution to the cycle is of second-order importance when the economy is hit by relatively small shocks, so it will not appear in our analysis based on a first-order approximation method.
} 
labor equations, discouraging investment and labor demand. Referring to the business cycle accounting work of Chari, Kehoe and McGrattan (2007), we notice that our financial friction manifests itself not only as an investment wedge but also a labor wedge.

Equation (2) shows how the debt overhang distortion affects the investment decision: a high leverage, $E\{\ln (b / y)\}$, implies a short distance to default, $d_{1}$, and a low repayment probability, $\Phi\left(d_{1}\right)$. The firm responds by increasing the term $E\{\partial y / \partial k\}$, i.e. by decreasing investment. An analogous argument applies to the labor hiring decision, as shown in equation (3).

It is worth noting that, as leverage, $E\{\ln (b / y)\}$, tends to zero, the default probability tends to zero as well, and the debt overhang distortion disappears. This suggests that the debt overhang effect may play a quantitatively more important role in periods when the business sector has already accumulated substantial debt.

\subsection{Equilibrium}

Let government spending $g$ follow the law of motion:

$$
\ln \left(g_{t+1}\right)=\rho_{g} \ln \left(g_{t}\right)+\sigma_{g} \varepsilon_{g, t+1}
$$

where $\varepsilon_{g, t+1}$ is an i.i.d. standard normal shock. Government spending is financed with lump-sum taxes: $g_{t}=T_{t}$.

The goods market equilibrium condition is

$$
c_{t}+k_{t+1}-(1-\delta) k_{t}+g_{t}=E_{t}\left\{\omega_{t}\right\} \theta_{t} A_{t} f\left(k_{t}, l_{t}\right)
$$

where $A_{t}=A\left(k_{t}^{\alpha} l_{t}^{1-\alpha}\right)^{1-\tau}$ in equilibrium.

The system describing the equilibrium is spelled out in Appendix C. Once the equilibrium has been determined, one can compute several variables related with credit risk. The interest rate on risky debt, the risky rate, $i$, is defined in terms of the ratio of the face value of debt and the amount of funds borrowed by firms,

$$
1+i_{t} \equiv \frac{b_{t+1}}{m}
$$

so the debt face value $b_{t+1}$ can be expressed as the sum of the principal, $m$, and interests, $i_{t} m$; and the credit spread is simply defined as the difference between the risky rate $i_{t}$ and the risk-free rate $r_{t}$. Appendix $\mathrm{D}$ defines the expected default frequency, the default rate, the loss rate, the loss given default, and the recovery rate.

\section{Results}

In this section, we document the model's quantitative predictions and compare them with data.

\subsection{Data and calibration}

Data are quarterly for the period 1981:I-2008:IV. We use output and hours (both Nonfarm Business Sector) from the Bureau of Labor Statistics, consumption (Nondurable Goods and Services), capital and investment (both Private Fixed Nonresidential) from the Bureau of Economic Analysis, default rates (All Rated) and recovery rates (All Bonds) 
from Moody's, and credit spreads (difference of Seasoned Baa Corporate Bond Yield and 10-Year Treasury Note Yield at Constant Maturity) from Moody's and the Treasury Department. The quarterly capital series has been obtained by interpolating the annual data.

Table 1 lists our benchmark parametrization. The values of all preferences and production parameters are standard. (The parameters $A$ and $\phi$ do not matter for the dynamics of the model.) The parameter $\tau$ controlling the returns-to-scale at the firm level is set low enough so that $f(k, l)$ is sufficiently concave and the second-order conditions for optimality in the firm's problem are satisfied. The returns to scale are constant at the aggregate level though.

The parameters of the technology process $\theta_{t}$ are estimated from the HP-filtered Solow residual. First, the autocorrelation and the volatility of the technology process are estimated. Then, the first-order autocorrelation of the log-volatility process is set equal to 1, following Justiniano and Primiceri (2008). Finally, the volatility of the log-volatility process is estimated via quasi-maximum-likelihood following Harvey, Ruiz and Shephard (1994).

The government spending parameters are standard and in line with estimates based on post-war US data. The steady state ratio of government spending to output is set to 0.18 , the persistence of the government spending process, $\rho_{g}$, to 0.95 , and the standard deviation of the shock, $\sigma_{g}$, to 0.015 .

Besides standard production parameters, two other parameters help determine the default rate: the level of funds, $m$, and the average volatility, $\sigma_{\omega}$ of the idiosyncratic productivity. Not only they help determine what is the steady state default probability $1-\Phi\left(d_{2}\right) \equiv 1-\Phi(\ln (y / b) / \sigma)$, but also how the default probability responds to shocks and to changes in the endogenous variables. We set those two parameters to match two conditions. First, the steady state probability of default is equal to $0.5 \%$, which is the mean of the quarterly default rate for All Corporates from Moody's. Also, $\Phi^{\prime}\left(d_{2}\right) / \sigma=0.5$ so the steady state probability of default increases by $0.5 \%$ as the steady state leverage ratio, $b / y$, increases by one percentage point.

The dynamics of the model is sensitive to this latter choice. The greater the fraction $\Phi^{\prime}\left(d_{2}\right) / \sigma$, the larger the response of the default probability and of the debt overhang distortion to shocks and to changes in the endogenous variables. As one decreases that fraction (by decreasing the steady state probability of default, or by increasing the volatility $\sigma$ for given steady state probability of default) the debt overhang distortion responds less and the size of the effects we are emphasizing in this paper diminish.

As a result of our calibration, in the steady state, the ratio of funds to quarterly output $m / y$ and the ratio of debt to quarterly output $b / y$ are equal to 0.923 and 0.928 respectively. Also, the volatility of idiosyncratic productivity, 0.0283 , is about five times the volatility of the aggregate productivity, 0.006 .

The final two parameters, $\rho_{\sigma, \omega}$ and $\sigma_{\sigma, \omega}$, govern the process for the log-volatility of the idiosyncratic productivity. The role played by these two parameters is negligible. They do not play any role in the solution of the model and do not affect any impulse response function, other than the impulse response function to the log-volatility itself. Hence, they can only affect the second moments of the model. Since there is no empirical evidence to reasonably calibrate or estimate these two parameters, we set the volatility of the log-volatility process equal to zero, so $\sigma_{\omega, t}$ is actually constant and equal to $\sigma_{\omega}$. We also note that, if instead one sets these two parameters equal to the corresponding one for the aggregate productivity, $\rho_{\sigma, \omega}=\rho_{\sigma, \theta}$ and $\sigma_{\sigma, \omega}=\sigma_{\sigma, \theta}$, the effect on the second 
moments is quantitatively negligible. The reason why we maintain the possibility of a variable log-volatility in the description of the model is that we find instructive showing the impulse response function to the log-volatility itself, and we set the autocorrelation $\rho_{\sigma, \omega}$ equal to 0.9 for this illustrative purpose.

\section{$3.2 \quad$ Impulse responses}

The crucial effect of the debt overhang distortion is on the equilibrium conditions determining investment and labor. From equations (2) and (3), disregarding the covariance terms and evaluating the equations at equilibrium, the following two conditions can be derived:

$$
\begin{aligned}
1 & =E_{t}\left\{\Lambda_{t, t+1}\right\}\left[1-\delta+E_{t}\left\{\omega_{t+1} \theta_{t+1}\right\} A_{t+1} f_{k}\left(k_{t+1}, l_{t+1}\right) \Phi\left(d_{1, t}\right)\right] \\
w_{t+1} & =E_{t}\left\{\Lambda_{t, t+1}\right\} E_{t}\left\{\omega_{t+1} \theta_{t+1}\right\} A_{t+1} f_{l}\left(k_{t+1}, l_{t+1}\right) \Phi\left(d_{1, t}\right) \\
\text { where } \Lambda_{t, t+1} & \equiv \beta u^{\prime}\left(c_{t+1}\right) / u^{\prime}\left(c_{t}\right) \\
A_{t+1} & =A\left(k_{t+1}^{\alpha} l_{t+1}^{1-\alpha}\right)^{1-\tau} \\
d_{1, t} & \equiv \frac{\rho_{\theta} \ln \left(\theta_{t}\right)+\ln \left(A_{t+1} f\left(k_{t+1}, l_{t+1}\right)\right)-\ln \left(b_{t+1}\right)}{\sigma_{t}}+\sigma_{t}
\end{aligned}
$$

and $f_{k}$ and $f_{l}$ denote the derivatives of $f$ with respect to its two arguments.

These two equations are similar to the corresponding ones of a standard real business cycle model with labor-in-advance, except for the presence of the probability of repayment $\Phi\left(d_{1, t}\right)$. As already noted, the default probability $1-\Phi\left(d_{1, t}\right)$ acts like a wedge discouraging investment and labor demand.

As a result, in the model with debt overhang, shocks affect the real economy through an additional channel, by affecting the distance to default $d_{1, t}$ and the default probability $1-\Phi\left(d_{1, t}\right)$. In addition to their standard effect, technology shocks affect the economy by affecting the distance to default and the default probability. Shocks that do not have an effect in the standard model, such as shocks to the volatility of productivity, have an effect here by affecting the default probability.

In addition, the effect of shocks gets amplified and propagated through two positive feedback loop mechanisms. The static mechanism works within one period through the feedback between the firms' investment and hiring decisions and the default probability: any shock that discourages capital and labor decreases the distance to default $d_{1}$ and increases the default probability $1-\Phi\left(d_{1}\right)$, which further discourages capital and labor. The dynamic mechanism works over time through the feedback between the firms' capital stock and the default probability: any shock that discourages investment and decreases the capital stock increases persistently the default probability, which further discourages future investment and capital.

Over the cycle, the default probability acts like a counter-cyclical tax, strengthening the firms' incentive to reduce investment and labor in periods when output is below trend, leverage is high, and the default probability is high. This is consistent with the countercyclical dynamics of the investment and labor wedges, documented by Chari, Kehoe and McGrattan (2007) and by Shimer (2010) (the latter focuses on the labor wedge only).

\section{Technology shocks}

Figure 1 shows the impulse response to an expansionary technology shock. The thick solid line refers to our debt overhang model, while the thin one refers to the corresponding 
model without any financial friction. We will comment on the dashed line, referring to a model with monitoring costs, below in Section 3.4.

The standard effect of an expansionary productivity shock consists in raising the expected marginal product of capital, thereby encouraging investment. The debt overhang distortion adds an additional effect: The expansionary productivity shock raises the distance to default $d_{1}$, thereby lowering the default probability and further encouraging investment. Notice the static feedback loop mechanism: an increase in capital and labor lowers the default probability which, in turn, leads to a further increase in the demand for capital and labor. Moreover, the debt overhang correction adds persistence to the propagation mechanism because the higher capital stock tends to lower the default probability for several periods, even as productivity returns to normal.

In line with the VAR evidence, the probability of default decreases substantially, implying a smaller investment wedge, a higher expected marginal return of the firms' investment, and a higher investment and future production. Labor responds similarly to investment. The qualitative response of all variables agrees with intuition: Credit spreads decrease, recovery rates increase, and default rates decrease. ${ }^{13}$

Because the lending rate increases, the face value of debt increases after an expansionary productivity shock. This tends to increase the probability of default and to weaken the effect of an expansionary productivity shock, so debt contributes negatively to the dynamic feedback loop mechanism. In numerical experiments, we find that the dynamics of debt does not fully offset the dynamics of capital, so that the effects of productivity shocks are always stronger and more persistent in the economy with debt overhang relatively to the model without it.

\section{Government spending shocks}

Figure 2 shows the impulse response to an expansionary government spending shock under the baseline calibration, $\rho_{g}=0.95$. In the initial periods, the presence of debt overhang magnifies the output response to government spending shocks. The labor response is positive and amplified, and this more than offsets the decrease of investment in physical capital due to crowding-out.

The persistence of the government spending process is, however, crucial in shaping the response of the economy over time. The greater the persistence, the smaller the crowding-out of investment, the greater the amplification.

Under the baseline calibration, $\rho_{g}=0.95$, government spending is sufficiently persistent, the crowding-out effect on investment is small, and the response of output is amplified by debt overhang for several years. As the persistence increases (e.g., $\rho_{g}=1$; figures not shown), the response of investment may even turn positive, and the amplification generated by the financial friction becomes even larger. The reason for this is that the shock permanently decreases households' income and wealth. This induces households to respond by decreasing consumption and leisure and increasing the labor supply. The marginal product of capital increases, investment is crowded-in, and the capital stock converges to a higher value. This generates a permanent reduction in the default rate and, thus, a permanent reduction in the debt overhang distortion.

\footnotetext{
${ }^{13}$ Notice that the recovery rate refers to the subset of firms that default. Hence, the effect on the recovery rate is the result of the effect on the recovery value per given firm and the effect on the selection of firms that default. The positive effect on the recovery value is then attenuated by the decrease in the default rate, which leaves firms with relatively lower idiosyncratic productivity in the pool of firms that default.
} 
When government spending is less persistent (e.g., $\rho_{g}<0.90$; figures not shown), the negative wealth effect does not sufficiently raise the labor supply, and the crowdingout effect on investment in physical capital eventually dominates. Even though initially output responds more than in the model without friction, after a sufficient number of periods, the effect of low investment weighs on the capital stock, reduces output and increases the default rate and the debt overhang distortion.

\section{Volatility and funding cost shocks}

Figures 3 and 4 respectively show the impulse response functions to a shock to the volatility of technology $\theta$ and the idiosyncratic productivity $\omega$. Both types of shocks do not have any effect in the log-linearized version of the model without financial frictions. In contrast, they have sizeable effects in the economy with debt overhang. Both shocks have very similar effects, the main difference being that the quantitative effect of the second shock is larger because the standard deviation of the idiosyncratic productivity process is calibrated to be larger than the one of the technology process. An unanticipated increase in volatility decreases the distances to default. As a result, default probabilities increase, and the expected marginal return from the firms' investment decrease. As the debt overhang distortion gets larger, investment and future production decrease. Notice that a shock that increases the volatility of the idiosyncratic productivity, by thickening the tail of firms that default, has an especially strong effect on the recovery rate and on the default rate.

It is also instructive to consider the response to a shock (with 0.9 autocorrelation) to the bank's expected discounted profits $\bar{V}^{b}$, shown in Figure 5. This can be interpreted as an exogenous increase in the premium that banks charge for their loans, and can proxy for shocks to several factors affecting firms' funding costs, such as rents due to banking market structure and power, or shocks to risk and liquidity premiums. Of course, the shock increases the risky rate and the credit spread. More importantly, the shock increases the firms' liability and probability of default, exacerbates the financial friction, and decreases the firms' expected marginal return from investment, which, in turn, decreases actual investment and future production. Credit spreads, loss rates and default rates increase, whereas recovery rates decrease.

Finally, notice that, in the debt overhang model, volatility shocks and funding cost shocks affect the aggregate economy only through the probability of default. Hence, within the context of the model, they can be interpreted as credit market shocks. Their impulse response function is in line with the empirical response to credit market shocks documented by Gilchrist, Yankov and Zakrajsek (2009), who show that credit market shocks cause large and persistent contractions in economic activity, including industrial production, manufacturing activity, consumption spending, employment, durable and nondurable goods orders.

\subsection{Correlations}

Tables 2 and 3 provide some evidence in support of the debt overhang model, by comparing the second moments of several variables of interest in the model and in the data. The variables are the growth rates of labor, investment, consumption and output, and the levels of credit spread, recovery rate and default rate. The moments are correlations with credit spread, with default rate, and with the output growth rate, and autocorrelations. 
The signs of all moments match the ones in the data. Also, the correlations of the credit variables, namely the credit spread, the recovery rate and the default rate, with output and investment are all consistent with data. The autocorrelations of the credit risk variables are also consistent with data. Finally, a comparison between the autocorrelations in the models with and without debt overhang reveals how the debt overhang distortion significantly enhances the persistence of the macro variables growth rates, helping to better match their empirical counterparts.

\subsection{Comparison with the monitoring cost friction}

Before contrasting our debt overhang model with a monitoring cost friction setup, we notice that the two underlying frictions are not alternative to each other. In agency costs models à la Bernanke, Gertler and Gilchrist (1999), the output level is not observable, and the friction arises from an asymmetric information problem between the lender and the firm. This friction discourages investment by increasing the marginal cost of investing: the external finance premium. In our model, the firm's non-contractible investment action affects the payoff of the lender, and the debt overhang is generated by a friction arising from a moral hazard problem. This friction discourages investment by decreasing the firm's private marginal benefit of investing. The debt overhang distortion is not present in monitoring costs models because investment is contractible - one can think that investment is chosen at the time the contract is signed. However, the two frictions, i.e. asymmetric information on output and moral hazard due to non-contractibility of investment, are likely to coexist and can be modeled together.

To compare the predictions of two frameworks, we add to the standard model with labor-in-advance and without debt overhang the monitoring costs financial friction described in Christiano, Motto and Rostagno (2003). ${ }^{14}$

The parameters specific to the monitoring costs friction are calibrated in the plausible way suggested by Bernanke, Gertler, and Gilchrist (1999). The calibration is as follows: the monitoring costs parameter is $\mu=0.12$; the average and autocorrelation of the entrepreneurs' survival probability are respectively $z^{*}=0.9845$ and $\rho_{z}=0.9$; the standard deviation of the idiosyncratic shock is $\sigma^{*}=0.28$. The other parameters are calibrated as in our model, as described in Table 1.

The dashed line in Figures 1, 4 and 5 refers to the impulse responses of the monitoring costs model. We do not plot the response to shocks to the volatility of technology, because they only have effects in our debt overhang economy. The first observation is that the qualitative response of most variables to shocks is similar in the two models, highlighting some common elements between the two frictions. Notice in particular the similarity of the response to a funding cost shock in the model with debt overhang with the response to a net worth shock in the model with monitoring costs, plotted in Figure 5. The qualitative response to a shock to the volatility of the idiosyncratic productivity is also similar in the two models (except for the recovery rate).

The monitoring costs model, however, does not have clear-cut predictions as to the sign of the response of credit spreads and default rates to technology shocks, as first pointed out by Carlstrom and Fuerst (1997). ${ }^{15}$ In their model, entrepreneurs finance their

\footnotetext{
${ }^{14}$ Appendix E briefly describes the friction. For a detailed description of the friction, see Bernanke, Gertler, and Gilchrist (1999) and Christiano, Motto, and Rostagno (2003).

${ }^{15}$ The following is the relevant excerpt from Carlstrom and Fuerst (1997): "The foremost problem is the cyclical behavior of bankruptcy rates and the risk premia. Because of our linearity assumptions,
} 
investment through their net worth or bank loans. After an expansionary productivity shock, since net worth is pre-determined, they need to borrow more in order to expand investment, which leads to counter-factually higher risk premia and bankruptcy rates. In other models with a financial friction based on agency monitoring costs, the sign of the responses of credit spreads and default rates to productivity shocks varies depending on the specific modeling assumptions and parameter values. In contrast, the response of credit spreads and default rates is always negative in our debt overhang framework. This is consistent with the negative correlations of both the default rate and the credit spread with the output growth rate found in the data (See Table 2).

Furthermore, the amplification mechanism of technology shock is quantitatively small in the model with monitoring costs, unless the monitoring costs are set equal to an un-plausibly high level. The reason behind the quantitative difference between the two models is instructive. In the model with monitoring costs, the credit spread is the sum of the default probability and the external finance premium. The financial friction, however, is related to the external finance premium only, which in turn is linked with the monitoring costs. When the monitoring costs tend to zero, although leverage and defaults are still present, they become irrelevant for the evolution of the aggregate variables. A plausible calibration of the monitoring costs leads to a very small variability of the external finance premium, and to a very small amplification mechanism. In contrast, in the model with debt overhang, the distortion is directly related to the default probability (there is no external finance premium), which varies sizeably both in the model and in the data.

The monitoring costs friction can lead to a larger amplification mechanism when it acts in combination with other features, as in the Bernanke, Gertler, and Gilchrist (1999) model. In numerical experiments, we found that the most important features of their model necessary for the friction to generate a large amplification mechanism are a variable price of capital, a very large (close to one) autocorrelation of the technology shock, and sticky prices together with a monetary policy rule implying a very small (about 1.1) monetary policy long-run response of the nominal interest rate to inflation. Given the monetary policy rule, the degree of persistence of the technology process has dramatic effects on the amplification mechanism. Indeed, when the autocorrelation of technology is small, the monitoring costs friction can lead to an attenuation mechanism. Notice however that, even under the parametrization of Bernanke, Gertler, and Gilchrist (1999), the amplification and propagation mechanism is substantially smaller than the one generated by the debt overhang distortion.

\subsection{Robustness}

As already pointed out, the dynamics of the model is particularly sensitive to parameters that affect the response of the default probability, $1-\Phi\left(d_{2, t}\right)$, to shocks and to changes in the endogenous variables.

The derivative of the default probability with respect to the distance to default, $d_{2, t} \equiv E_{t} \ln \left(y_{t+1} / b_{t+1}\right) / \sigma_{t}$, is $-\Phi^{\prime}\left(d_{2, t}\right)$, i.e., minus the density of the standard normal random distribution evaluated at the distance to default. The greater the steady state

these variables are functions solely of the aggregate price of capital. Hence, the increase in the price of capital that occurs with a positive technology shock also leads to an increase in bankruptcy rates and risk premia. From a theoretical perspective this behavior is not surprising: The supply curve for capital is upward sloped because of agency costs, so that a demand-induced movement up this curve must imply an increase in risk premia." 
default probability, $1-\Phi\left(d_{2}\right)$, the greater the steady state density $\Phi^{\prime}\left(d_{2}\right)$ (for values of the default probability less than $50 \%$ ), the greater the response of the default probability to changes in the distance to default. Hence, the debt overhang amplification and propagation mechanism tends to be more powerful for larger values of the steady state default probability, $1-\Phi\left(d_{2}\right)$. Hence, larger values for the steady state leverage ratio, $b / y$ raise the steady state default probability and tend to enhance the debt overhang mechanism.

Changes in the steady state volatility, $\sigma$, affect the dynamics of the default probability in two ways. On one hand, a larger value of the volatility, $\sigma$, raises the default probability, $1-\Phi\left(d_{2}\right)$, and tends to enhance the debt overhang mechanism. On the other hand, the derivative of the default probability with respect to leverage, $E_{t} \ln \left(b_{t+1} / y_{t+1}\right)$, is $\Phi^{\prime}\left(d_{2, t}\right) / \sigma_{t}$; so, for given steady state density, $\Phi^{\prime}\left(d_{2}\right)$, a larger value of the volatility, $\sigma$, lowers the response of the default probability to changes in leverage, and tends to dampen the debt overhang mechanism.

As pointed out in the introduction, debt overhang distorts a wide range of discretionary decisions. In particular, it discourages both investment in physical capital and labor demand. To capture the labor distortion, one needs a framework where labor is chosen after the debt contract is signed but before the uncertainty about default is resolved. This led us to assume that labor is chosen one period in advance, before the realizations of the shocks become known. ${ }^{16}$

One implication of this timing assumption is that labor, i.e. total hours, responds with one period delay to shocks. Two points deserve to be stressed. First, the implications of this timing may be plausible. In the macro literature with search (e.g. Andolfatto (1996)), it is commonly assumed that employment (the extensive margin) is pre-determined. Although hours per worker (the intensive margin) can respond to contemporaneous shocks, they are not very variable and explain only about $1 / 3$ of the volatility of total hours. This suggests that a model where labor is pre-determined may indeed generate plausible predictions on labor response to aggregate shocks and on labor dynamics. The second point is that whether labor is distorted by debt overhang is conceptually independent of whether labor responds to contemporaneous shocks. As long as there remains some risk of default, labor will be distorted by debt overhang regardless of whether it can or cannot respond to contemporaneous shocks.

How would the debt overhang mechanism be modified if labor could respond to contemporaneous aggregate shocks but were still distorted by debt overhang? To investigate the effect of a different timing assumption on the debt overhang mechanism, we made a simple experiment. We modified the labor demand and supply equations assuming that the labor choice is made in the same period as that of production, after the aggregate shocks are revealed, but before the realization of the idiosyncratic productivity shock, so some default risk is still present and labor is still distorted by debt overhang. More specifically, we let $L_{t+1}$ be a control variable chosen after the realizations of the aggregate shocks, and we substituted $\Phi\left(d_{1, t}^{\omega}\right)$ for $\Phi\left(d_{1, t}\right)$ in the labor demand equation (3). We found that the amplification and propagation mechanism is practically unchanged (except, of course, for the initial period). This suggests that the time when labor is chosen and whether labor is predetermined or can respond to contemporaneous shocks do not play important roles in the mechanism, as long as some default risk remains at the time of the labor choice.

\footnotetext{
${ }^{16}$ Other frameworks could be adopted. For instance, an interesting alternative would be introducing time to produce, as in the recent work of Schwartzman (2010), where current labor and capital affect future production.
} 
How would our results be modified if labor were not distorted by debt overhang? To examine the contribution of the labor distortion to the amplification and propagation mechanism, we further modified the labor demand equation, assuming that the labor choice is not distorted by debt overhang and deleting $\Phi\left(d_{1, t}^{\omega}\right)$ altogether from the labor demand equation (3). In this case, the debt overhang mechanism works through the investment channel only. The qualitative effects of the debt overhang distortion are similar to the ones that we have documented. Quantitatively, the debt overhang distortion continues to have a very persistent effect through its effect on physical capital; however, the amplification mechanism is substantially reduced, as expected. We also considered a model with a fixed labor input and we found a similar persistent effect and a similar reduction in the amplification mechanism. This suggests that the persistence is primarily determined by the distortion on investment in physical capital while the initial amplification mechanism works mainly through the labor distortion.

\section{Conclusion}

In this paper, we have studied the business cycle implications of the debt overhang distortion described by Myers (1977). The dynamics of this distortion, which moves countercyclically, amplify and propagate the response of a standard business cycle model to technology, government spending, volatility and funding cost shocks. The model correlations of investment, output and credit risk variables are consistent with data.

While there are many interesting issues that can be studied with extensions of the model, exploring its policy implications seems especially promising. Since the response of investment to shocks is larger than is socially optimal, a role for counter-cyclical policies arises. A counter-cyclical subsidy to investment or a pro-cyclical tax on profits could partly offset the larger debt overhang distortion during recessions. The policy implications of our framework are likely to differ from the ones that stem from traditional models with financial frictions because in those models investment is constrained by credit market conditions while in our setting it is the overhang of existing debt that generates underinvestment.

Finally, in a debt overhang economy with nominal debt, monetary policy can have real effects via an additional balance sheet debt-deflation channel: The unanticipated component of inflation lowers the real value of debt, strengthens firms' balance sheets, lowers the debt overhang distortion, and encourages investment and production. Studying this mechanism is especially interesting today, when traditional interest rate channels of monetary policy are less effective.

\section{Acknowledgements}

We would like to thank Pedro Amaral, Chuck Carlstrom, Huberto Ennis, Urban Jermann, Juan Rubio-Ramírez, Christina Wang and seminar participants at the Joint Central Bank Conference held in Zurich, the Federal Reserve System Macro Meeting, the Midwest Macroeconomics Meetings, the Workshop on Macroeconomic Dynamics held at EIEF, Rome, the Federal Reserve Bank of Cleveland, the Federal Reserve Board of Governors, the International Monetary Fund, Kent State University, Oberlin College, and Ohio State University. 


\section{References}

Andolfatto, D., 1996. Business Cycles and Labor-Market Search. The American Economic Review 86(1), 112-132.

Bernanke, B. S., and M. Gertler, 1989. Agency Costs, Net Worth, and Business Fluctuations. The American Economic Review 79(1), 14-31.

Bernanke, B. S., Gertler, M., and Gilchrist, S., 1999. The Financial Accelerator in a Quantitative Business Cycle Framework. In J. B. Taylor and M. Woodford (ed.), Handbook of Macroeconomics, volume 1, chapter 21, 1341-1393.

Bolton, P., and Dewatripont, M., 2005. Contract Theory. The MIT Press.

Bulow, J., and Rogoff, K., 1991. Sovereign Debt Repurchases: No Cure for Overhang. The Quarterly Journal of Economics 106(4), 1219-1235.

Carlstrom, C. T., and Fuerst, T. S., 1997. Agency Costs, Net Worth, and Business Fluctuations: A Computable General Equilibrium Analysis. American Economic Review 87(5), 893-910.

Chari, V. V., P. J. Kehoe, and E. R. McGrattan, 2007. Business Cycle Accounting. Econometrica 75(3), 781-836.

Chen, H., and Manso, G., 2010. Macroeconomic Risk and Debt Overhang. Unpublished manuscript.

Christiano, L. J., Motto, R., and Rostagno, M., 2003. The Great Depression and the Friedman-Schwartz Hypothesis. Journal of Money, Credit and Banking 35(6), 1119-1197.

Christiano, L. J., Motto, R., and Rostagno, M. 2007. Financial Factors in Business Cycles. Unpublished manuscript.

Cooley, T., Marimon, R., and Quadrini, V., 2004. Aggregate Consequences of Limited Contract Enforceability. Journal of Political Economy 112(4), 817-847.

Córdoba, J. C., and Ripoll, M., 2004. Credit Cycles Redux. International Economic Review 45(4), 1011-1046.

Freixas, X., and Rochet, J. C., 2008. Microeconomics of Banking. The MIT Press.

Gilchrist, S., Ortiz, A., and Zakrajsek, E., 2009. Credit Risk and the Macroeconomy: Evidence from an Estimated DSGE Model. Unpublished manuscript.

Gilchrist, S., Yankov, V., and Zakrajsek, E., 2009. Credit Market Shocks and Economic Fluctuations: Evidence from Corporate Bond and Stock Markets. Journal of Monetary Economics 56, 471-493.

Harvey, A., Ruiz, E., and Shephard, N., 1994. Multivariate Stochastic Variance Models. The Review of Economic Studies 61(2), 247-264.

Hennessy, C. A., 2004. Tobin's Q, Debt Overhang, and Investment. The Journal of Finance 59(4), 1717-1742.

Hennessy, C. A., Levy, A., and Whited, T. M., 2007. Testing Q Theory with Financing Frictions. Journal of Financial Economics 83, 691-717.

Innes, R. D., 1990. Limited Liability and Incentive Contracting with Ex-ante Action Choices. Journal of Economic Theory 52, 45-67.

Jermann, U. J., and Quadrini, V., 2009. Macroeconomic Effects of Financial Shocks. Unpublished manuscript.

Justiniano, A., and Primiceri, G. E., 2008. The Time-Varying Volatility of Macroeconomic Fluctuations. American Economic Review 98(3), 604-641.

Kiyotaki, N., and Moore, J., 1997. Credit Cycles. The Journal of Political Economy 105(2), 211-248. 
Kocherlakota, N. R., 2000. Creating Business Cycles Through Credit Constraints. Federal Reserve Bank of Minneapolis Quarterly Review 24(3), 210.

Krugman, P., 1988. Financing vs. Forgiving a Debt Overhang. Journal of Development Economics 29(3), 253-268.

Lamont, O., 1995. Corporate-Debt Overhang and Macroeconomic Expectations The American Economic Review 85(5), 1106-1117.

Merz, M., 1995. Search in the Labor Market and the Real Business Cycle. Journal of Monetary Economics 36, 269-300.

Moyen, N., 2007. How Big Is the Debt Overhang Problem? Journal of Economic Dynamics and Control 31, 433-472.

Myers, S. C., 1977. Determinants of Corporate Borrowing. Journal of Financial Economics 5, 147-175.

Obstfeld, M., and Rogoff, K., 1996. Foundations of International Macroeconomics. The MIT Press.

Philippon, T., 2009. The Macroeconomics of Debt Overhang. Unpublished manuscript presented at the 10th Jacques Polak Annual Research Conference hosted by the International Monetary Fund.

Schwartzman, F., 2010. Time to Produce and Emerging Market Crises. Federal Reserve Bank of Richmond Working Paper No. 10-15.

Shimer, R., 2010. Labor Markets and Business Cycles. Princeton University Press.

\section{A Contracting problem}

This appendix shows that the contracting problem (1) in Section 2.4, is the same as the one studied by Innes (1990).

In analogy with the contract theory literature, it is convenient to define the firm investment "effort" $e \equiv f(k, l)$, and to introduce the cost function

$$
\psi(e) \equiv \min _{k, l}\{w l+[1-E\{\Lambda\}(1-\delta)] k\} \text { subject to } f(k, l) \geq e
$$

Since the production function $f(k, l)$ is increasing and concave, the cost function $\psi(e)$ is increasing and convex.

Then, the objective function of the firm becomes

$$
V^{f}(P(y), e) \equiv E\{\Lambda[y-P(y)]\}-\psi(e)+m
$$

where output is equal to $y=\omega \theta A e$, and problem (1) can be restated as:

$$
\begin{aligned}
& \max _{P(y), e^{*}} V^{f}\left(P(y), e^{*}\right) \\
& \text { subject to } 0 \leq P(y) \leq y \text { all } y \\
& P\left(y_{1}\right) \leq P\left(y_{2}\right) \text { all } y_{1} \leq y_{2} \\
& V^{f}(P(y), e) \leq V^{f}\left(P\left(y^{*}\right), e^{*}\right) \text { all } e \geq \underline{e} \\
& V^{b}\left(P\left(y^{*}\right)\right) \geq \bar{V}^{b}
\end{aligned}
$$

for given $\bar{V}^{b}$, where $e^{*}$ is the equilibrium effort choice by the firm, and $y^{*} \equiv \omega \theta A e^{*}$ is the corresponding output level. The required minimum investment level is captured by 
$\underline{e}>0$. The third constraint simply states that $e^{*}$ is the level of effort that maximizes the firm's objective function.

This is the same problem as the one studied by Innes (1990), except that the two objective functions $V^{f}(P(y), e)$ and $V^{b}(P(y))$ are expressed differently. To obtain alternative expressions for the two objective functions, let $g(y \mid e)$ be the density function of output conditional on effort, so $E\{\cdot\} \equiv \int\{\cdot\} g(y \mid e) d y$. Given our assumptions on $\theta$ and $\omega, g$ is a $\log$-normal density: $\log (y)$ is normally distributed with mean equal to $\rho_{\theta} \ln \left(\theta_{-1}\right)+\log (A e)$ and standard deviation equal to $\sigma$. It is easy to show that $g(y \mid e)$ satisfies the monotone likelihood ratio property, so a higher realization of output indicates a greater likelihood of higher effort:

Proposition. For all $e_{2}>e_{1}$, the likelihood ratio $\frac{g\left(y \mid e_{2}\right)}{g\left(y \mid e_{1}\right)}$ is strictly increasing in $y$.

Proof. Since $\omega$ and $\theta$ are $\log$-normally distributed, $g(y \mid e)$ is also log-normal:

$$
g(y \mid e)=\frac{1}{y \sqrt{2 \pi \sigma^{2}}} \exp \left(-\frac{1}{2} \frac{[\ln (y)-\mu(e)]^{2}}{\sigma^{2}}\right)
$$

where $\mu(e) \equiv \rho_{\theta} \ln \left(\theta_{-1}\right)+\log (A e)$ is strictly increasing in $e$. Hence, for all $e_{2}>e_{1}$, $\mu\left(e_{2}\right)>\mu\left(e_{1}\right)$, and the likelihood ratio

$$
\begin{aligned}
\frac{g\left(y \mid e_{2}\right)}{g\left(y \mid e_{1}\right)} & =\exp \left(-\frac{1}{2} \frac{\left[\ln (y)-\mu\left(e_{2}\right)\right]^{2}-\left[\ln (y)-\mu\left(e_{1}\right)\right]^{2}}{\sigma^{2}}\right) \\
& =\exp \left(-\frac{1}{2} \frac{[\ln (y)]^{2}+\left[\mu\left(e_{2}\right)\right]^{2}-2 \ln (y) \mu\left(e_{2}\right)-[\ln (y)]^{2}-\left[\mu\left(e_{1}\right)\right]^{2}+2 \ln (y) \mu\left(e_{1}\right)}{\sigma^{2}}\right) \\
& =\exp \left(-\frac{1}{2} \frac{\left[\mu\left(e_{2}\right)\right]^{2}-\left[\mu\left(e_{1}\right)\right]^{2}}{\sigma^{2}}+\frac{\mu\left(e_{2}\right)-\mu\left(e_{1}\right)}{\sigma^{2}} \ln (y)\right)
\end{aligned}
$$

is strictly increasing in $y$.

Then, the objective functions of the firm and the bank can be expressed as follows:

$$
\begin{aligned}
V^{f}(P(y), e) & \equiv \int\{\Lambda[y-P(y)]\} g(y \mid e) d y-\psi(e)+m \\
V^{b}(P(y)) & \equiv \int\{\Lambda P(y)\} g(y \mid e) d y-m
\end{aligned}
$$

Next, we transform the probability space introducing the probability density function $\tilde{g}(y \mid e) \equiv \Lambda g(y \mid e) / \tilde{\beta}$, where $\tilde{\beta} \equiv \int \Lambda g(y \mid e) d y$ is the normalizing scalar that ensures that $\int \tilde{g}(y \mid e) d y=1$, so $\tilde{g}(y \mid e)$ is a probability density function. The mapping between the two measures implies $E\{\Lambda \cdot\}=\tilde{\beta} \tilde{E}\{\cdot\}$, where $\tilde{E}$ is the expectation operator with respect to the new density $\tilde{g}$. With the same steps used earlier in the case of $g(y \mid e)$, one can show that $\tilde{g}(y \mid e)$ also satisfies the monotone likelihood ratio property.

The objective functions of the firm and the bank become:

$$
\begin{aligned}
V^{f}(P(y), e) & \equiv \tilde{\beta} \int\{y-P(y)\} \tilde{g}(y \mid e) d y-\psi(e)+m \\
V^{b}(P(y)) & \equiv \tilde{\beta} \int\{P(y)\} \tilde{g}(y \mid e) d y-m
\end{aligned}
$$

These two expressions are the same as the ones in Innes (1990). The contracting problem (1) is, then, the same as the one studied by Innes (1990), who shows that the solution is risky debt. 


\section{B Analytical results for log-normals}

This appendix applies some analytical results holding for the expectation of the minimum of log-normal random variables, and for its derivatives, in order to derive equations (2) and (3).

Notice that $A_{t+1}, k_{t+1}, l_{t+1}$ and $b_{t+1}$ are all known in period $\mathrm{t}+1$, and that $y_{t+1}=$ $\omega_{t+1} \theta_{t+1} A_{t+1} f\left(k_{t+1}, l_{t+1}\right)$ is log-normally distributed with standard deviation equal to $\sigma_{t}$. Then, an analytical result holding for log-normally distributed random variables yields

$$
\begin{aligned}
E_{t}\left\{\min \left\{y_{t+1}, b_{t+1}\right\}\right\} & =E_{t}\left\{y_{t+1}\right\}\left[1-\Phi\left(d_{1, t}\right)\right]+b_{t+1} \Phi\left(d_{2, t}\right) \\
\text { where } d_{2, t} & \equiv \frac{E_{t}\left\{\ln \left(y_{t+1}\right)\right\}-\ln \left(b_{t+1}\right)}{\sigma_{t}} \text { and } d_{1, t} \equiv d_{2, t}+\sigma_{t}
\end{aligned}
$$

where $\Phi(\cdot)$ is the cumulative distribution function of the standard normal random variable.

Turning to the derivatives, and dropping the time subscripts to ease notation,

$$
\begin{aligned}
\frac{\partial E\{\min \{y, b\}\}}{\partial k} & =\frac{\partial\left[E\{y\}\left[1-\Phi\left(d_{1}\right)\right]+b \Phi\left(d_{2}\right)\right]}{\partial k} \\
& =E\{\partial y / \partial k\}\left[1-\Phi\left(d_{1}\right)\right]-E\{y\} \Phi^{\prime}\left(d_{1}\right) \frac{\partial d_{1}}{\partial k}+b \Phi^{\prime}\left(d_{2}\right) \frac{\partial d_{2}}{\partial k} \\
& =E\{\partial y / \partial k\}\left[1-\Phi\left(d_{1}\right)\right]
\end{aligned}
$$

where the last step follows from $\frac{\partial d_{1}}{\partial k}=\frac{\partial d_{2}}{\partial k}$ and from

$$
\begin{aligned}
-E\{y\} \Phi^{\prime}\left(d_{1}\right)+b \Phi^{\prime}\left(d_{2}\right) & =-e^{\ln (E\{y\})} \Phi^{\prime}\left(d_{1}\right)+e^{\ln (b)} \Phi^{\prime}\left(d_{2}\right) \\
& =-e^{\ln (E\{y\})} \frac{1}{\sqrt{2 \pi}} e^{-\frac{1}{2} d_{1}^{2}}+e^{\ln (b)} \frac{1}{\sqrt{2 \pi}} e^{-\frac{1}{2} d_{2}^{2}} \\
& =-e^{\ln (E\{y\})} \frac{1}{\sqrt{2 \pi}} e^{-\frac{1}{2}\left(d_{2}^{2}+2 d_{2} \sigma+\sigma^{2}\right)}+e^{\ln (b)} \frac{1}{\sqrt{2 \pi}} e^{-\frac{1}{2} d_{2}^{2}} \\
& =-e^{\ln (E\{y\})} \frac{1}{\sqrt{2 \pi}} e^{-\frac{1}{2} d_{2}^{2}} e^{-\left[d_{2} \sigma+\frac{1}{2} \sigma^{2}\right]}+e^{\ln (b)} \frac{1}{\sqrt{2 \pi}} e^{-\frac{1}{2} d_{2}^{2}} \\
& =-e^{\ln (E\{y\})} \frac{1}{\sqrt{2 \pi}} e^{-\frac{1}{2} d_{2}^{2}} e^{-\left[E\{\ln (y)\}-\ln (b)+\frac{1}{2} \sigma^{2}\right]}+e^{\ln (b)} \frac{1}{\sqrt{2 \pi}} e^{-\frac{1}{2} d_{2}^{2}} \\
& =-e^{\ln (E\{y\})} \frac{1}{\sqrt{2 \pi}} e^{-\frac{1}{2} d_{2}^{2}} e^{-\left[\ln E\{y\}-\frac{1}{2} \sigma^{2}-\ln (b)+\frac{1}{2} \sigma^{2}\right]}+e^{\ln (b)} \frac{1}{\sqrt{2 \pi}} e^{-\frac{1}{2} d_{2}^{2}} \\
& =-e^{\ln (E\{y\})} \frac{1}{\sqrt{2 \pi}} e^{-\frac{1}{2} d_{2}^{2}} e^{-[\ln (E\{y\})-\ln (b)]}+e^{\ln (b)} \frac{1}{\sqrt{2 \pi}} e^{-\frac{1}{2} d_{2}^{2}} \\
& =-\frac{1}{\sqrt{2 \pi}} e^{-\frac{1}{2} d_{2}^{2}} e^{\ln (b)}+e^{\ln (b)} \frac{1}{\sqrt{2 \pi}} e^{-\frac{1}{2} d_{2}^{2}} \\
& =0
\end{aligned}
$$

Similarly,

$$
\frac{\partial E\{\min \{y, b\}\}}{\partial l}=E\{\partial y / \partial l\}\left[1-\Phi\left(d_{1}\right)\right]
$$




\section{Solution}

This appendix spells out the system describing the equilibrium.

Using an analytical result holding for log-normally distributed random variables, the bank's participation constraint becomes:

$$
\begin{aligned}
& m+\bar{V}_{t}^{b}=E\left\{\Lambda_{t, t+1} \min \left\{y_{t+1}, b_{t+1}\right\}\right\} \\
& m+\bar{V}_{t}^{b}=E_{t}\left\{\Lambda_{t, t+1}\right\}\left\{E_{t}\left\{y_{t+1}\right\}\left[1-\Phi\left(d_{1, t}\right)\right]+b_{t+1} \Phi\left(d_{2, t}\right)\right\}+\partial \operatorname{Cov}_{t} / \partial b_{t+1}
\end{aligned}
$$

where

$$
\begin{aligned}
\operatorname{Cov}_{t} & \equiv \operatorname{Cov}_{t}\left(\Lambda_{t, t+1}, \min \left\{y_{t+1}, b_{t+1}\right\}\right) \\
d_{2, t} & \equiv \frac{E_{t}\left\{\ln \left(y_{t+1}\right)\right\}-\ln \left(b_{t+1}\right)}{\sigma_{t}} \text { and } d_{1, t} \equiv d_{2, t}+\sigma_{t}
\end{aligned}
$$

Then, the system describing the equilibrium is:

$$
\begin{aligned}
\ln \left(\theta_{t+1}\right) & =\rho_{\theta} \ln \left(\theta_{t}\right)+\sigma_{\theta, t} \varepsilon_{\theta, t+1}, \\
\ln \left(\sigma_{\theta, t+1} / \sigma_{\theta}\right) & =\rho_{\theta, \sigma} \ln \left(\sigma_{\theta, t} / \sigma_{\theta}\right)+\sigma_{\theta, \sigma} \eta_{\theta, t+1} \\
\ln \left(\omega_{t+1}\right) & =\sigma_{\omega, t} \varepsilon_{\omega, t+1} \\
\ln \left(\sigma_{\omega, t+1} / \sigma_{\omega}\right) & =\rho_{\omega, \sigma} \ln \left(\sigma_{\omega, t} / \sigma_{\omega}\right)+\sigma_{\omega, \sigma} \eta_{\omega, t+1} \\
\sigma_{t}^{2} & \equiv \sigma_{\omega, t}^{2}+\sigma_{\theta, t}^{2} \\
A_{t}= & A\left(k_{t}^{\alpha} l_{t}^{1-\alpha}\right)^{1-\tau} \\
u^{\prime}\left(c_{t}\right) w_{t+1}= & \beta v^{\prime}\left(l_{t+1}\right) \\
m+\bar{V}_{t}^{b}= & E_{t}\left\{\Lambda_{t, t+1}\right\}\left\{E_{t}\left\{y_{t+1}\right\}\left[1-\Phi\left(d_{1, t}\right)\right]+b_{t+1} \Phi\left(d_{2, t}\right)\right\}+\partial \operatorname{Cov}_{t} / \partial b_{t+1} \\
1 & =E_{t}\left\{\Lambda_{t, t+1}\right\}\left[1-\delta+E_{t}\left\{\omega_{t+1} \theta_{t+1}\right\} A_{t+1} f_{k}\left(k_{t+1}, l_{t+1}\right) \Phi\left(d_{1, t}\right)\right]+\partial \operatorname{Cov}_{t} / \partial k_{t+1} \\
w_{t+1}= & E_{t}\left\{\Lambda_{t, t+1}\right\} E_{t}\left\{\omega_{t+1} \theta_{t+1}\right\} A_{t+1} f_{l}\left(k_{t+1}, l_{t+1}\right) \Phi\left(d_{1, t}\right)+\partial \operatorname{Cov}_{t} / \partial l_{t+1} \\
c_{t}+k_{t+1}= & (1-\delta) k_{t}+E_{t}\left\{\omega_{t}\right\} \theta_{t} A_{t} f\left(k_{t}, l_{t}\right) \\
\text { where } \Lambda_{t, t+1} \equiv \beta u^{\prime}\left(c_{t+1}\right) / u^{\prime}\left(c_{t}\right) & y_{t} \equiv \omega_{t} \theta_{t} A_{t} f\left(k_{t}, l_{t}\right) \\
& \operatorname{Cov}_{t} \equiv \operatorname{Cov}_{t}\left(\Lambda_{t, t+1}, \min \left\{y_{t+1}, b_{t+1}\right\}\right) \\
& d_{2, t} \equiv \frac{\rho_{\theta} \ln \left(\theta_{t}\right)+\ln \left(A_{t+1} f\left(k_{t+1}, l_{t+1}\right)\right)-\ln \left(b_{t+1}\right)}{\sigma_{t}} \text { and } d_{1, t} \equiv d_{2, t}+\sigma_{t}
\end{aligned}
$$

This system can be solved with standard methods, log-linearizing it around its nonstochastic steady state. Notice that the derivatives of the covariance terms disappear from the log-linearized approximation because, in the non-stochastic steady state, the covariances are identically equal to zero, so their derivatives are equal to zero as well. 
The following is the log-linear approximation of our equilibrium system:

$$
\begin{aligned}
\hat{\theta}_{t+1} & =\rho_{\theta} \hat{\theta}_{t}+\sigma_{\theta} \varepsilon_{\theta, t+1} \\
\hat{\sigma}_{\theta, t+1} & =\rho_{\theta, \sigma} \hat{\sigma}_{\theta, t}+\sigma_{\theta} \sigma_{\theta, \sigma} \eta_{\theta, t+1} \\
\hat{\sigma}_{\omega, t+1} & =\rho_{\omega, \sigma} \hat{\sigma}_{\omega, t}+\sigma_{\omega} \sigma_{\omega, \sigma} \eta_{\omega, t+1} \\
\sigma \hat{\sigma}_{t} & =\sigma_{\omega} \hat{\sigma}_{\omega, t}+\sigma_{\theta} \hat{\sigma}_{\theta, t} \\
-\gamma \hat{c}_{t}+\hat{w}_{t+1} & =\varphi \hat{l}_{t+1} \\
-\gamma \hat{c}_{t} & =-\gamma \hat{c}_{t+1}+\frac{\beta}{m}\left\{y\left[1-\Phi\left(d_{1}\right)\right]\left[\hat{y}_{t+1}-\frac{\Phi^{\prime}\left(d_{1}\right)}{1-\Phi\left(d_{1}\right)} \hat{d}_{1, t}\right]+b \Phi\left(d_{2}\right)\left[\hat{b}_{t+1}+\Phi^{\prime}\left(d_{2}\right) \hat{d}_{2, t}\right]\right\} \\
-\gamma \hat{c}_{t} & =-\gamma \hat{c}_{t+1}+[1-\beta(1-\delta)]\left\{\hat{y}_{t+1}-\hat{k}_{t+1}+\frac{\Phi^{\prime}\left(d_{1}\right)}{\Phi\left(d_{1}\right)} \hat{d}_{1, t}\right\} \\
-\gamma \hat{c}_{t}+\hat{w}_{t+1} & =-\gamma \hat{c}_{t+1}+\hat{y}_{t+1}-\hat{l}_{t+1}+\frac{\Phi^{\prime}\left(d_{1}\right)}{\Phi\left(d_{1}\right)} \hat{d}_{1, t} \\
c \hat{c}_{t}+k \hat{k}_{t+1} & =(1-\delta) k \hat{k}_{t}+y \hat{y}_{t} \\
\text { where } \hat{y}_{t} & \equiv \hat{\theta}_{t}+\alpha \hat{k}_{t}+(1-\alpha) \hat{l}_{t} \\
\hat{d}_{2, t} & \equiv \frac{\rho_{\theta} \hat{\theta}_{t}+\alpha \hat{k}_{t+1}+(1-\alpha) \hat{l}_{t+1}-\hat{b}_{t+1}-\frac{d_{2}}{\sigma} \hat{\sigma}_{t} \text { and } \hat{d}_{1, t} \equiv \hat{d}_{2, t}+\hat{\sigma}_{t}}{\sigma}
\end{aligned}
$$

where hatted variables represent deviations (in the case of $\sigma, \sigma_{\theta}, \sigma_{\omega}, d_{1}$ and $d_{2}$ ) or log-deviations (in the case of all other variables) from steady state, whereas non-hatted variables represent steady state values.

\section{Credit risk variables}

This appendix defines some additional credit risk variables that we consider in our paper.

Recall that there is a continuum of mass 1 of firms. Let firms be indexed by $i \in[0,1]$. Let $\omega_{t}(i)$ be the idiosyncratic productivity shock, i.i.d. across all the firms indexed by $i \in[0,1]$. Notice that, because $\omega_{t}(i)$ is i.i.d. across a continuum of firms indexed by $i \in[0,1], \int_{i=0}^{1} h\left(\omega_{t}(i)\right) d i=E_{t} h\left(\omega_{t}\right)$ for a generic function $h$, where $\omega_{t}$ is a random variable (unknown in period $t$ ) distributed as $\omega_{t}(i)$. In other words, the average of a variable across firms is equal to the expectation of the same variable for one firm, prior to the realization of $\omega_{t}$. The following definitions follow.

Expected default frequency (Probability of default):

$$
\begin{aligned}
E D F_{t} & \equiv \operatorname{Prob}_{t}\left\{\omega_{t+1} \theta_{t+1} A_{t+1} f\left(k_{t+1}, l_{t+1}\right) \leq b_{t+1}\right\} \\
& =\operatorname{Prob}_{t}\left\{\frac{\ln \left(\omega_{t+1} \theta_{t+1}\right)-\rho_{\theta} \ln \left(\theta_{t}\right)}{\sigma_{t}} \leq \frac{\ln \left(b_{t+1}\right)-\ln \left(A_{t+1} f\left(k_{t+1}, l_{t+1}\right)\right)-\rho_{\theta} \ln \left(\theta_{t}\right)}{\sigma_{t}}\right\} \\
& =\Phi\left(-d_{2, t}\right) \\
& =1-\Phi\left(d_{2, t}\right) \\
\text { where } d_{2, t} & \equiv \frac{\rho_{\theta} \ln \left(\theta_{t}\right)+\ln \left(A_{t+1} f\left(k_{t+1}, l_{t+1}\right)\right)-\ln \left(b_{t+1}\right)}{\sigma_{t}}
\end{aligned}
$$

and $\Phi(\cdot)$ is the cumulative distribution function of the standard normal random variable. 
Default rate:

$$
\begin{aligned}
D R_{t} & \equiv \int_{i=0}^{1} I\left\{\omega_{t}(i) \theta_{t} A_{t} f\left(k_{t}(i), l_{t}(i)\right) \leq b_{t}(i)\right\} d i \\
& =\operatorname{Prob}_{t}\left\{\omega_{t} \theta_{t} A_{t} f\left(k_{t}, l_{t}\right) \leq b_{t}\right\} \\
& =\operatorname{Prob}_{t}\left\{\frac{\ln \left(\omega_{t}\right)}{\sigma_{\omega, t-1}} \leq \frac{\ln \left(b_{t}\right)-\ln \left(\theta_{t} A_{t} f\left(k_{t}, l_{t}\right)\right)}{\sigma_{\omega, t-1}}\right\} \\
& =\Phi\left(-d_{2, t}^{\omega}\right) \\
& =1-\Phi\left(d_{2, t}^{\omega}\right) \\
\text { where } d_{2, t}^{\omega} & \equiv \frac{\ln \left(\theta_{t} A_{t} f\left(k_{t}, l_{t}\right)\right)-\ln \left(b_{t}\right)}{\sigma_{\omega, t-1}} \text { and } d_{1, t}^{\omega} \equiv d_{2, t}^{\omega}+\sigma_{\omega, t-1}
\end{aligned}
$$

and $I(\cdot) \in\{0,1\}$ is the indicator function, equal to 1 when its argument is true.

Loss rate:

$$
\begin{aligned}
L R_{t} & \equiv \frac{\int_{i=0}^{1} \max \left\{b_{t}(i)-\omega_{t}(i) \theta_{t} A_{t} f\left(k_{t}(i), l_{t}(i)\right), 0\right\} d i}{\int_{i=0}^{1} b_{t}(i) d i} \\
& =\frac{E_{t} \max \left\{b_{t}-\omega_{t} \theta_{t} A_{t} f\left(k_{t}, l_{t}\right), 0\right\}}{b_{t}} \\
& =\frac{\left(1-\Phi\left(d_{2, t}^{\omega}\right)\right) b_{t}-\left(1-\Phi\left(d_{1, t}^{\omega}\right)\right) \theta_{t} A_{t} f\left(k_{t}, l_{t}\right)}{b_{t}} \\
& =\left(1-\Phi\left(d_{2, t}^{\omega}\right)\right)-\left(1-\Phi\left(d_{1, t}^{\omega}\right)\right) \frac{\theta_{t} A_{t} f\left(k_{t}, l_{t}\right)}{b_{t}}
\end{aligned}
$$

where $E_{t}$ is the average with respect to $\omega_{t}$.

Loss given default:

$$
\begin{aligned}
L G D_{t} & \equiv \frac{\int_{i=0}^{1} \max \left\{b_{t}(i)-\omega_{t}(i) \theta_{t} A_{t} f\left(k_{t}(i), l_{t}(i)\right), 0\right\} d i}{\int_{i=0}^{1} b_{t}(i) I\left\{\omega_{t}(i) \theta_{t} A_{t} f\left(k_{t}(i), l_{t}(i)\right) \leq b_{t}(i)\right\} d i} \\
& =E_{t}\left\{\frac{b_{t}-\omega_{t} \theta_{t} A_{t} f\left(k_{t}, l_{t}\right)}{b_{t}} \mid \omega_{t} \theta_{t} A_{t} f\left(k_{t}, l_{t}\right) \leq b_{t}\right\} \\
& =\frac{1}{b_{t}} E_{t}\left\{b_{t}-\omega_{t} \theta_{t} A_{t} f\left(k_{t}, l_{t}\right) \mid \omega_{t} \theta_{t} A_{t} f\left(k_{t}, l_{t}\right) \leq b_{t}\right\} \\
& =\frac{1}{b_{t}} \frac{E_{t} \max \left\{b_{t}-\omega_{t} \theta_{t} A_{t} f\left(k_{t}, l_{t}\right), 0\right\}}{D R_{t}} \\
& =\frac{1}{b_{t}} \frac{\left(1-\Phi\left(d_{2, t}^{\omega}\right)\right) b_{t}-\left(1-\Phi\left(d_{1, t}^{\omega}\right)\right) \theta_{t} A_{t} f\left(k_{t}, l_{t}\right)}{1-\Phi\left(d_{2, t}^{\omega}\right)} \\
& =1-\frac{1-\Phi\left(d_{1, t}^{\omega}\right)}{1-\Phi\left(d_{2, t}^{\omega}\right)} \frac{\theta_{t} A_{t} f\left(k_{t}, l_{t}\right)}{b_{t}}
\end{aligned}
$$

Recovery rate:

$$
R R_{t} \equiv 1-L G D_{t}=\frac{1-\Phi\left(d_{1, t}^{\omega}\right)}{1-\Phi\left(d_{2, t}^{\omega}\right)} \frac{\theta_{t} A_{t} f\left(k_{t}, l_{t}\right)}{b_{t}}
$$




\section{E The monitoring costs financial friction}

In this appendix, we briefly describe the monitoring costs financial friction, based on Bernanke, Gertler and Gilchrist (1999), that we add to a standard model with labor-inadvance for the purpose of comparing its effect with the debt overhang distortion.

Households supply funds to a perfectly competitive banking sector at the risk free rate $R_{t}$. In turn, banks lend those funds to risk-neutral entrepreneurs at the risky rate $R_{t+1}^{e}$. Entrepreneurs combine their own funds $N_{t+1}$ with the bank loans $B_{t+1}$, and purchase capital $K_{t+1}$ at a price $Q_{t}$ :

$$
Q_{t} K_{t+1}=N_{t+1}+B_{t+1}
$$

We neglect investment adjustment costs, so output is freely transformable into capital and consumption, and the price of capital relative to consumption, $Q_{t}$, is one.

After capital is purchased, each entrepreneur is subject to an idiosyncratic shock, $\omega_{t+1}$, with distribution $F\left(\omega_{t+1} ; \sigma_{\omega, t}\right)$, that changes the level of capital from $K_{t+1}$ to $\omega_{t+1} K_{t+1}$. The next period, entrepreneurs rent their capital to firms at the rental rate $R_{t+1}^{k}$ and firms produce output from capital and labor. Finally, after production occurs, the entrepreneur receives back the depreciated capital, $(1-\delta) \omega_{t+1} K_{t+1}$, and pays his debt to the banks. The loan, however, is risky, because the entrepreneur's liability is limited to the rent that he receives, so the entrepreneur effectively repays

$$
\min \left\{\omega_{t+1} R_{t+1}^{k} Q_{t} K_{t+1}, R_{t+1}^{e} B_{t+1}\right\}
$$

It is useful to define a threshold $\bar{\omega}_{t+1}$ such that all entrepreneurs for whom $\omega_{t+1}<\bar{\omega}_{t+1}$ have not enough resources to repay the debt, so $F\left(\bar{\omega}_{t+1}\right)$ is the default rate:

$$
\bar{\omega}_{t+1} R_{t+1}^{k} Q_{t} K_{t+1}=R_{t+1}^{e} B_{t+1}
$$

Credit market frictions arise because the realization of $\omega_{t+1}$ is observable to the lender only after paying a monitoring cost $\mu \omega_{t+1} R_{t+1}^{k} Q_{t} K_{t+1}$, with $0 \leq \mu<1$. In equilibrium, banks pay the costs to monitor all the entrepreneurs that default.

The equilibrium rates and external finance premium are determined by two key conditions. The first one is the zero-profit condition for banks, which is assumed to hold state-by-state: ${ }^{17}$

$$
\left[1-F\left(\bar{\omega}_{t+1}\right)\right] R_{t+1}^{e} B_{t+1}+\int_{0}^{\bar{\omega}_{t+1}}(1-\mu) \omega R_{t+1}^{k} Q_{t} K_{t+1} d F(\omega)=R_{t} B_{t+1}
$$

The ex-post revenues from banking activity - the interest payments plus the recovered values net of monitoring costs - must equal the banks' cost of funds.

The second condition follows from the solution of an optimal loan contract between banks and entrepreneurs. The optimal contract maximizes the entrepreneurs' expected wealth at the end of the contract

$$
E_{t}\left\{\int_{\bar{\omega}_{t+1}}^{\infty} \omega R_{t+1}^{k} Q_{t} K_{t+1} d F(\omega)-\left[1-F\left(\bar{\omega}_{t+1}\right)\right] R_{t+1}^{e} B_{t+1}\right\}
$$

\footnotetext{
${ }^{17} \mathrm{~A}$ consequence of this assumption is that $R_{t+1}^{e}$, the lending rate between $t$ and $t+1$, will be a function of the $t+1$ aggregate shocks, which rules out both banks' default and positive profits. The state-contingent nature of the debt contract makes more difficult the mapping of the lending rate $R^{e}$ to a data counterpart.
} 
Table 1: Benchmark parameter and steady state values

\begin{tabular}{ccl} 
Parameter & Value & Description \\
\hline \hline$\alpha$ & 0.33 & Capital share in the production function \\
$\tau$ & 0.614 & Returns to scale at the firm level \\
$\delta$ & 0.025 & Depreciation rate of capital \\
\hline$\beta$ & 0.995 & Preference discount factor \\
$\gamma$ & 1 & Relative risk aversion \\
$\varphi$ & 1 & Inverse of labor supply elasticity \\
\hline$\rho_{\theta}$ & 0.7 & Autocorrelation of technology \\
$\sigma_{\theta}$ & 0.006 & Volatility of technology \\
$\rho_{\sigma, \theta}$ & 1 & Autocorrelation of technology log-volatility \\
$\sigma_{\sigma, \theta}$ & 0.0758 & Volatility of technology log-volatility \\
\hline$\sigma_{\omega}$ & 0.0283 & Volatility of idiosyncratic productivity \\
$\rho_{\sigma, \omega}$ & 0.9 & Autocorrelation of idiosyncratic-productivity log-volatility \\
$\sigma_{\sigma, \omega}$ & 0 & Volatility of idiosyncratic-productivity log-volatility \\
\hline$\rho_{g}$ & 0.95 & Autocorrelation of government spending \\
$\sigma_{g}$ & 0.015 & Volatility of government spending \\
\hline $1-\Phi_{\left(d_{2}\right)}$ & 0.005 & Probability of default \\
$m / y$ & 0.923 & Ratio of starting funds to output \\
$b / y$ & 0.928 & Ratio of debt face value to output \\
$\bar{V} b$ & 0 & Banks' expected profits \\
\hline \hline
\end{tabular}

given the banks' zero-profit condition.

The solution of the contracting problem gives, after some manipulations, a relation between the external finance premium, $E_{t}\left\{R_{t+1}^{k}\right\} / R_{t}-1$, and the default threshold, $\bar{\omega}_{t+1}$, that can be expressed as

$$
E_{t}\left\{g\left(\bar{\omega}_{t+1}\right)\left[R_{t+1}^{k} / R_{t}-\tilde{g}\left(\bar{\omega}_{t+1}\right)\right]\right\}=0
$$

where $g$ and $\tilde{g}$ are functions of $\bar{\omega}_{t+1}$ (and $\sigma_{\omega, t}$ ). When the monitoring costs are zero, $\mu=0$, both $g$ and $\tilde{g}$ are identically equal to one, i.e. $g\left(\bar{\omega}_{t+1}\right) \equiv 1$ and $\tilde{g}\left(\bar{\omega}_{t+1}\right) \equiv 1$, for all $\bar{\omega}_{t+1}$. This implies that the expected return on capital must equal the risk-free rate, $E_{t} R_{t+1}^{k}=R_{t}$, as in the linearized standard business cycle model: even though defaults may occur, $F(\bar{\omega})>0$, the external finance premium is zero and no financial accelerator arises. 
Table 2: Correlations with credit spread, default rates and output

\begin{tabular}{lcccccc} 
& \multicolumn{2}{c}{ Corr. with } & \multicolumn{2}{c}{ Corr. with } & \multicolumn{2}{c}{ Corr. with } \\
& \multicolumn{2}{c}{ Credit Spread } & \multicolumn{2}{c}{ Default Rate } & \multicolumn{2}{c}{ Output } \\
& Model & Data & Model & Data & Model & Data \\
\hline \hline Investment & -0.3379 & -0.5805 & -0.2190 & -0.5261 & 0.9683 & 0.3545 \\
Consumption & -0.3265 & -0.3162 & -0.3591 & -0.1900 & 0.4300 & 0.5141 \\
Production & -0.3985 & -0.4398 & -0.2664 & -0.2038 & 1.0000 & 1.0000 \\
Credit Spread & 1.0000 & 1.0000 & 0.9432 & 0.3952 & -0.3985 & -0.4398 \\
Recovery Rate & -0.8881 & -0.2137 & -0.9292 & -0.6514 & 0.2160 & 0.2251 \\
Default Rate & 0.9432 & 0.3952 & 1.0000 & 1.0000 & -0.2664 & -0.2038 \\
\hline \hline
\end{tabular}

Table 3: First-order autocorrelations

\begin{tabular}{lccc} 
& $\begin{array}{c}\text { Model without } \\
\text { Debt Overhang }\end{array}$ & Model & Data \\
\hline \hline Investment & 0.0895 & 0.2125 & 0.5464 \\
Consumption & 0.0707 & 0.0831 & 0.4664 \\
Production & 0.1257 & 0.2682 & 0.4213 \\
Credit Spread & - & 0.7931 & 0.8090 \\
Recovery Rate & - & 0.8596 & 0.9804 \\
Default Rate & - & 0.8544 & 0.7560 \\
\hline \hline
\end{tabular}




\section{Response to a technology shock}
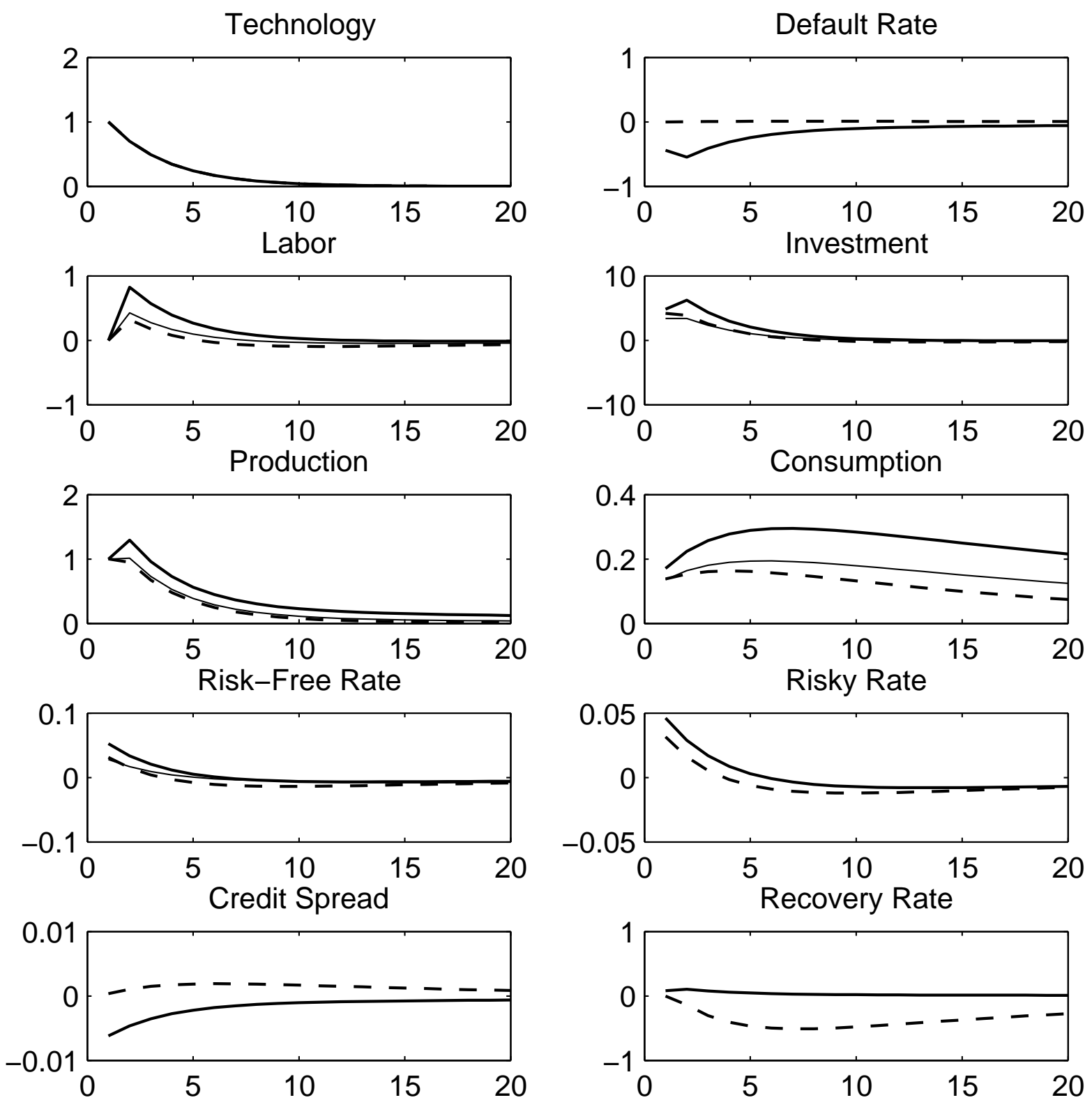

Figure 1: Model response to an expansionary technology shock. The thick solid, thin solid and dashed lines respectively refer to our debt overhang model, a corresponding model without any financial friction, and a model with a monitoring costs financial friction. 


\section{Response to a government spending shock}

Government Spending
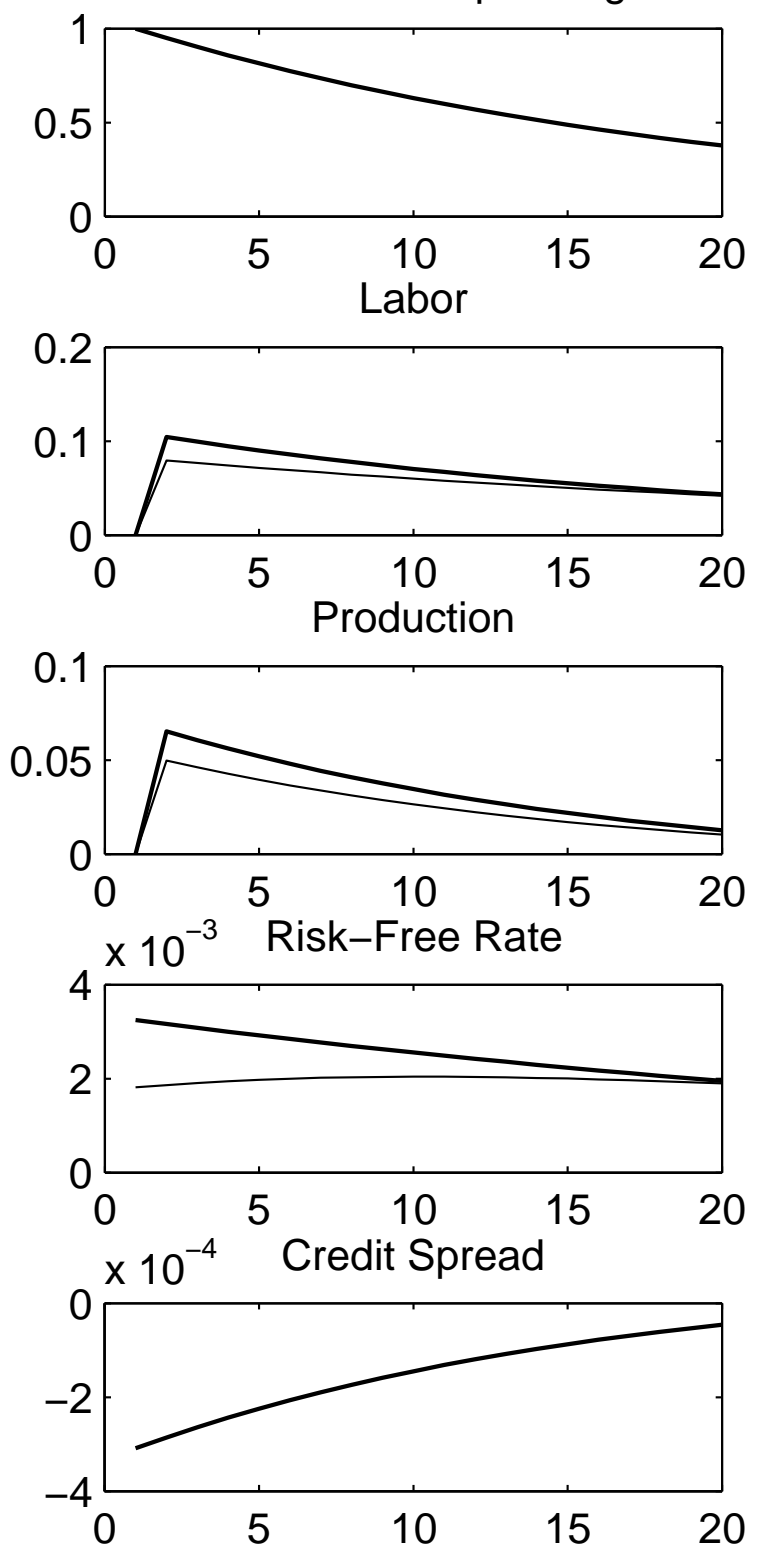

Default Rate
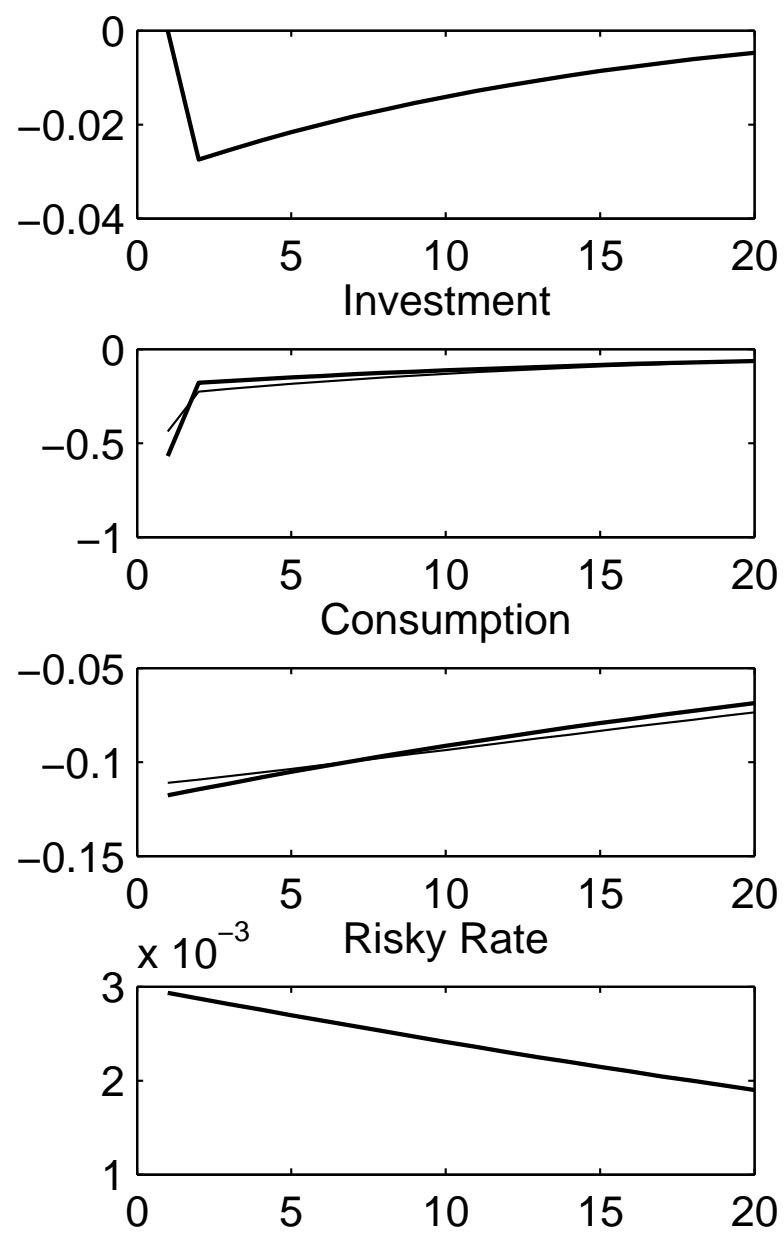

Recovery Rate

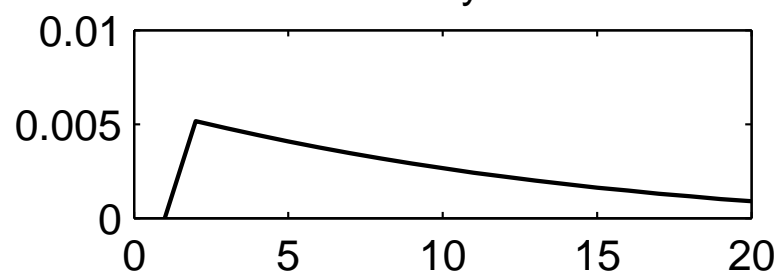

Figure 2: Model response to an expansionary government spending shock. The thick solid and thin solid lines respectively refer to our debt overhang model, and the corresponding model without any financial friction. 


\section{Response to the volatility of technology}
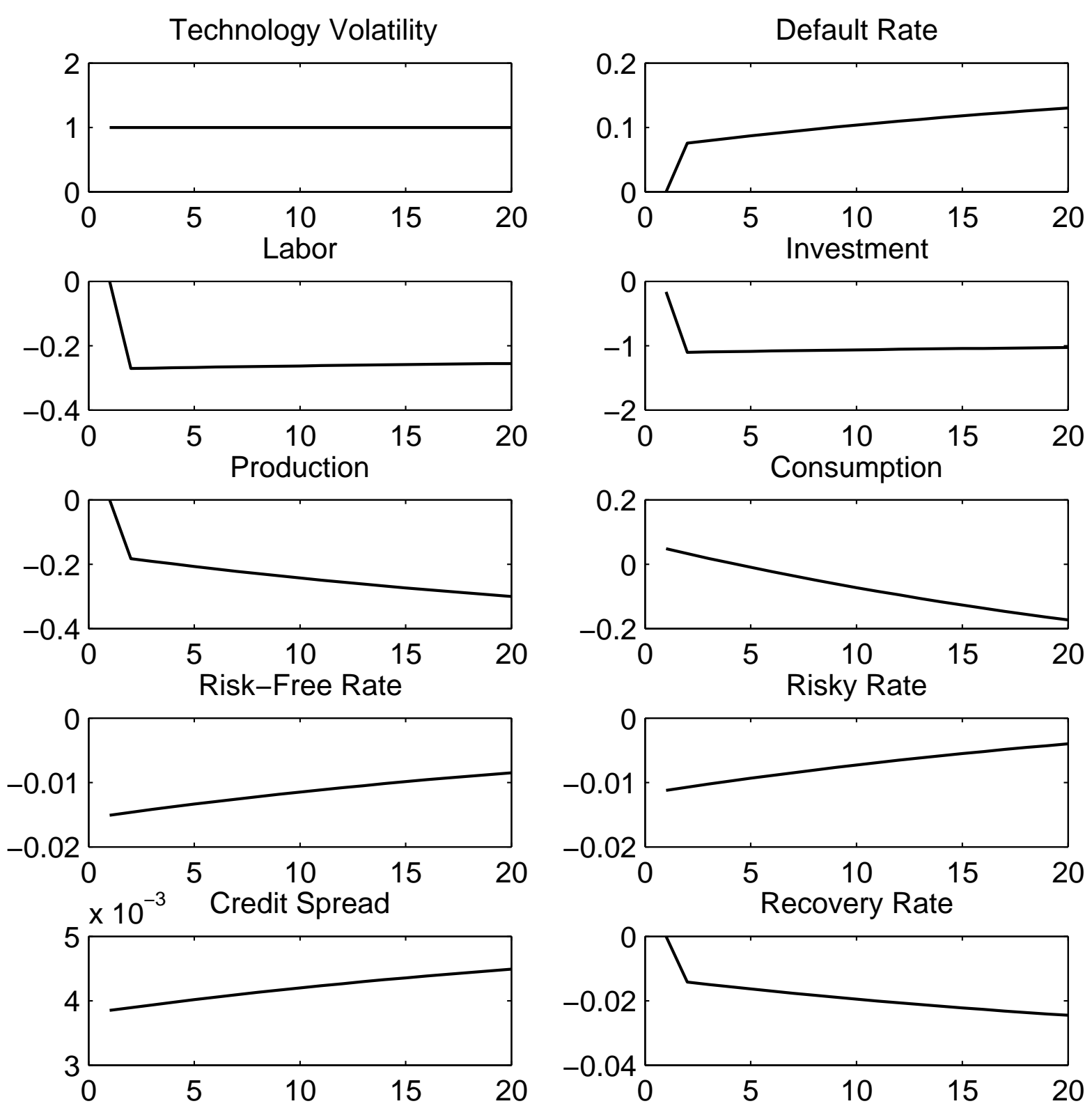

Figure 3: Model response to a positive shock to the volatility of technology. The thick solid line refers to our debt overhang model. 


\section{Response to the volatility of idiosyncratic productivity}
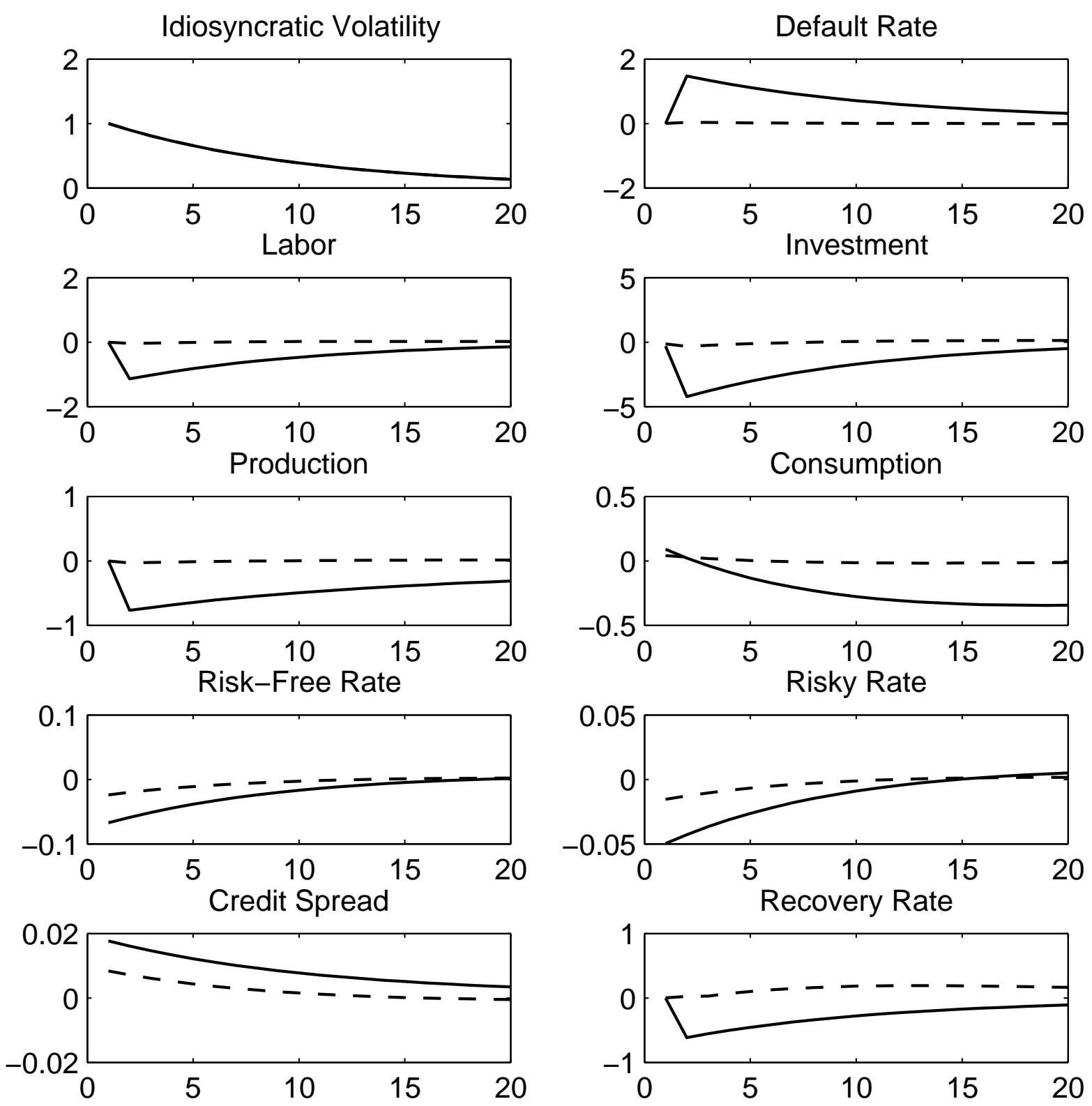

Figure 4: Model response to a positive shock to the volatility of idiosyncratic productivity. The thick solid and dashed lines respectively refer to our debt overhang model, and a model with a monitoring costs financial friction. 


\section{Response to a funding cost shock}

Debt
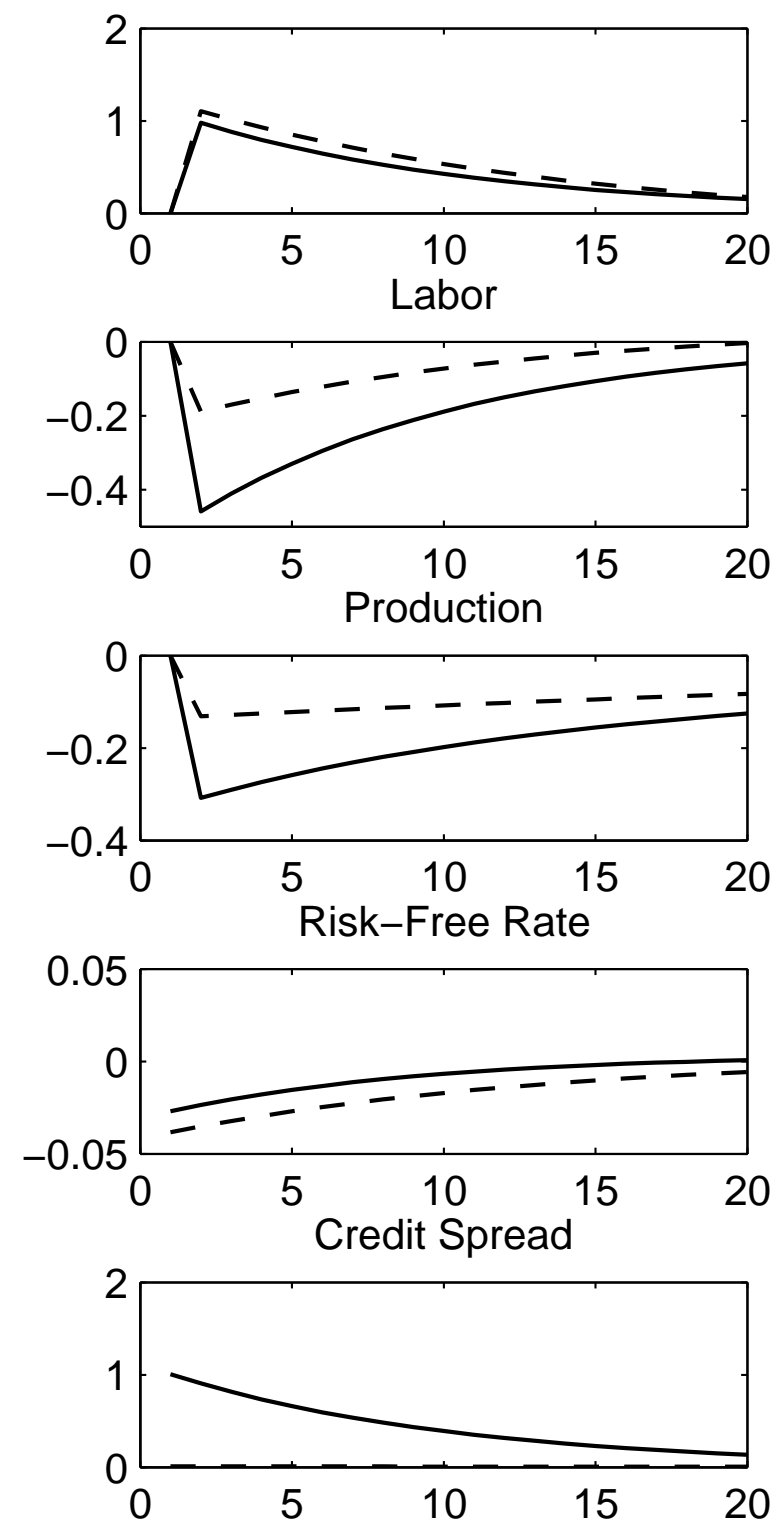

Default Rate
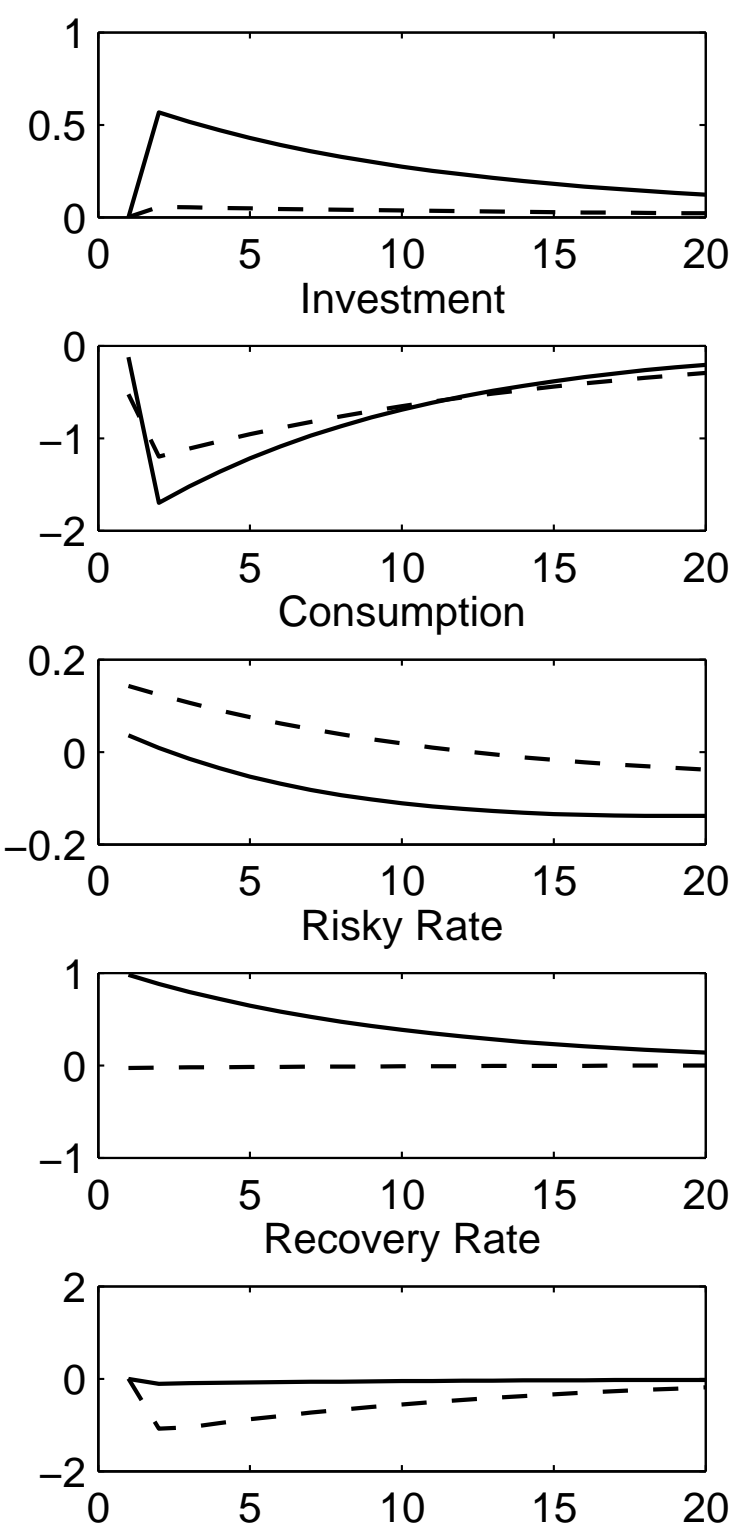

Figure 5: Model response to a shock increasing the funding costs. The thick solid and dashed lines respectively refer to our debt overhang model, and a model with a monitoring costs financial friction. For the latter model, we plot the response to a net worth shock. 